\title{
Metamorfismo de alto gradiente $P / T$ en la Sierra de Pie de Palo (Sierras Pampeanas, Argentina): modelado de equilibrio de fases minerales e implicancias geodinámicas en el antearco famatiniano
}

\author{
Carlos Dino Ramacciotti ${ }^{1,2}$, César Casquet ${ }^{3}$, Edgardo Gaspar Baldo ${ }^{1,2}$, Sebastián Osvaldo Verdecchia ${ }^{1,2}$, \\ Matías Martín Morales Cámera ${ }^{1,2}$, Priscila Soledad Zandomeni ${ }^{1,2}$
}

\begin{abstract}
I Universidad Nacional de Córdoba. Facultad de Ciencias Exactas, Físicas y Naturales. Córdoba, Argentina. Avda. Vélez Sarsfield 1611, Ciudad Universitaria, X5016CA Córdoba, Argentina. carlosramacciotti@yahoo.com.ar; edgardo.baldo@unc.edu.ar; sverdecchia@gmail.com; matiasmoralesc@gmail.com; priscilazandomeni@hotmail.com

2 Consejo Nacional de Investigaciones Cientificas y Tecnológicas (CONICET), Centro de investigaciones en Ciencias de la Tierra, (CICTERRA), Haya de la Torre s/n, Ciudad Universitaria, Córdoba, Argentina.

3 Departamento de Mineralogía y Petrología, Facultad de Ciencias Geológicas, Instituto de Geociencias (IGEO, CSIC), Universidad Complutense de Madrid, 28040 Madrid, España.

casquet@ucm.es
\end{abstract}

\begin{abstract}
RESUMEN. La Sierra de Pie de Palo (SPP, Sierras Pampeanas Occidentales) presenta evidencia de dos metamorfismos: uno de edad mesoproterozoica (orogenia Grenvilliana) y otro de edad ordovícica (orogenia Famatiniana). Este último es el único registrado en las secuencias sedimentarias neoproterozoicas-cámbricas que forman la cubierta del basamento grenvilliano. Un esquisto estaurolítico procedente de la Secuencia Metasedimentaria Difunta Correa (Ediacarense) en el sector suroriental de la SPP permite deducir, mediante la construcción de pseudosecciones, una evolución prograda desde los $c a .3 \mathrm{kbar}$ y $515^{\circ} \mathrm{C}$ hasta los $c a .9$ kbar y $640^{\circ} \mathrm{C}$ correspondiente a un alto gradiente $P / T$. Junto con Loma de Las Chacras, ubicada inmediatamente al este del área de estudio, la Sierra de Pie de Palo forma parte del antearco famatiniano el cual muestra variaciones de $P$ - $T$ transversalmente al arco magmático famatiniano. Dichas variaciones se registran como una disminución de $P$ (desde $c a .13$ hasta $6 \mathrm{kbar}$ ), $T$ (desde $c a .900$ hasta $450{ }^{\circ} \mathrm{C}$ ) y gradiente geotérmico (desde ca. 85 hasta $35^{\circ} \mathrm{C} / \mathrm{kbar}$ ) desde el área adyacente al arco magmático al este (Loma de Las Chacras) en dirección hacia el margen continental activo al oeste. El sector más próximo al mismo es el Grupo Caucete en el flanco occidental de la Sierra de Pie de Palo. El metamorfismo ocurrió, aparentemente, de forma sincrónica con el magmatismo famatiniano y con un sistema de infra-corrimientos dúctiles de vergencia oeste, a los $c a$. 470-465 Ma como consecuencia de la inhumación del antearco por debajo del arco magmático.
\end{abstract}

Palabras clave: Orogenia Famatiniana, Ordovícico, Antearco, Metamorfismo de alto gradiente P/T, Sierras Pampeanas Occidentales.

\begin{abstract}
High $P / T$ metamorphism in the Sierra de Pie de Palo (Sierras Pampeanas, Argentina): mineral phase equilibria modelling and geodynamic implications for the Famatinian forearc. The Sierra de Pie de Palo (SPP, Western Sierras Pampeanas) shows evidence of two regional metamorphisms: one Mesoproterozoic attributed to the Grenvillian orogeny and other of Ordovician age related to the Famatinian orogeny. The Neoproterozoic-to-Cambrian sedimentary successions that cover the Grenvillian basement only record the Ordovician event. One staurolite-schist from the Ediacaran Difunta Correa Metasedimentary Sequence collected in the southeastern side of the SPP allows to constrain, by means of pseudosections, a prograde evolution from $c a .3 \mathrm{kbar}$ and $515^{\circ} \mathrm{C}$ up to $c a .9 \mathrm{kbar}$ and $640{ }^{\circ} \mathrm{C}$ corresponding to a high $P / T$ gradient. The SPP and the immediately east Loma de Las Chacras outcrop were part of the famatinian forearc which shows a progressive decrease of $P$ (from $c a .13 \mathrm{kbar}$ to $6 \mathrm{kbar}$ ), $T$ (from $c a .900^{\circ} \mathrm{C}$ to $450{ }^{\circ} \mathrm{C}$ ), and $\mathrm{P} / \mathrm{T}$ gradient (from $\mathrm{ca} .85^{\circ} \mathrm{C} / \mathrm{kbar}$ to $35^{\circ} \mathrm{C} / \mathrm{kbar}$ ) towards the active continental margin on the west. The Caucete Group, in the western side of the SPP, represents the westernmost part of the forearc, near to the active continental margin. Metamorphism was apparently coeval with the Famatinian magmatism and with ductile underthrusting at ca. 470-465 Ma, which led to burial of the forearc beneath the magmatic arc.
\end{abstract}




\section{Introducción}

Las Sierras Pampeanas de Argentina constituyen un laboratorio natural excepcional donde se exponen rocas asociadas a procesos geológicos atribuidos a la formación y ruptura del supercontinente Rodinia (Meso-Neoproterozóico; e.g., Vujovich y Kay, 1998; Baldo et al., 2006; Colombo et al., 2009; Rapela et al., 2010; Varela et al., 2011) y a la formación de Gondwana (Neoproterozoico-Paleozoico Inferior; e.g., Rapela et al., 1998). Esta singularidad ocurre como consecuencia de la subducción plana de la placa de Nazca por debajo de la placa Sudamericana durante el Mioceno, entre los $c a .27^{\circ}$ y $33^{\circ} \mathrm{S}$ la cual exhuma bloques de basamento ígneo-metamórfico en el antepaís andino (Jordan y Allmendinger, 1986). Durante el Paleozoico inferior se desarrollaron, en el margen suroeste (SO) de Gondwana, dos orogenias que se encuentran ampliamente representadas en las
Sierras Pampeanas: orogenia Pampeana (Cámbrico Inferior) y orogenia Famatiniana (Ordovícico) (Fig. 1). La orogenia Pampeana se encuentra representada por un arco magmático calcoalcalino y rocas metamórficas de bajo a alto grado metamórfico de $c a$. 545-520 Ma (Casquet et al., 2018 y referencias allí citadas) mientras que la orogenia Famatiniana desarrolla un arco magmático de ca. 490-460 Ma (e.g., Pankhurst et al., 1998, 2000) y metamorfismo regional entre 480-440 Ma (e.g., Casquet et al., 2001; Lucassen y Becchio, 2003; Steenken et al., 2006; Mulcahy et al., 2011, 2014). Esta última ha sido atribuida a la colisión del terreno exótico Precordillera con el margen SO de Gondwana, con diferentes hipótesis respecto al origen y edad de acreción de dicho terreno (Ramos et al., 2004; Finney et al., 2007 y referencias allí citadas). Una de las ideas más aceptadas postula que este terreno se habría separado de Laurentia en el Cámbrico Inferior y habría colisionado en

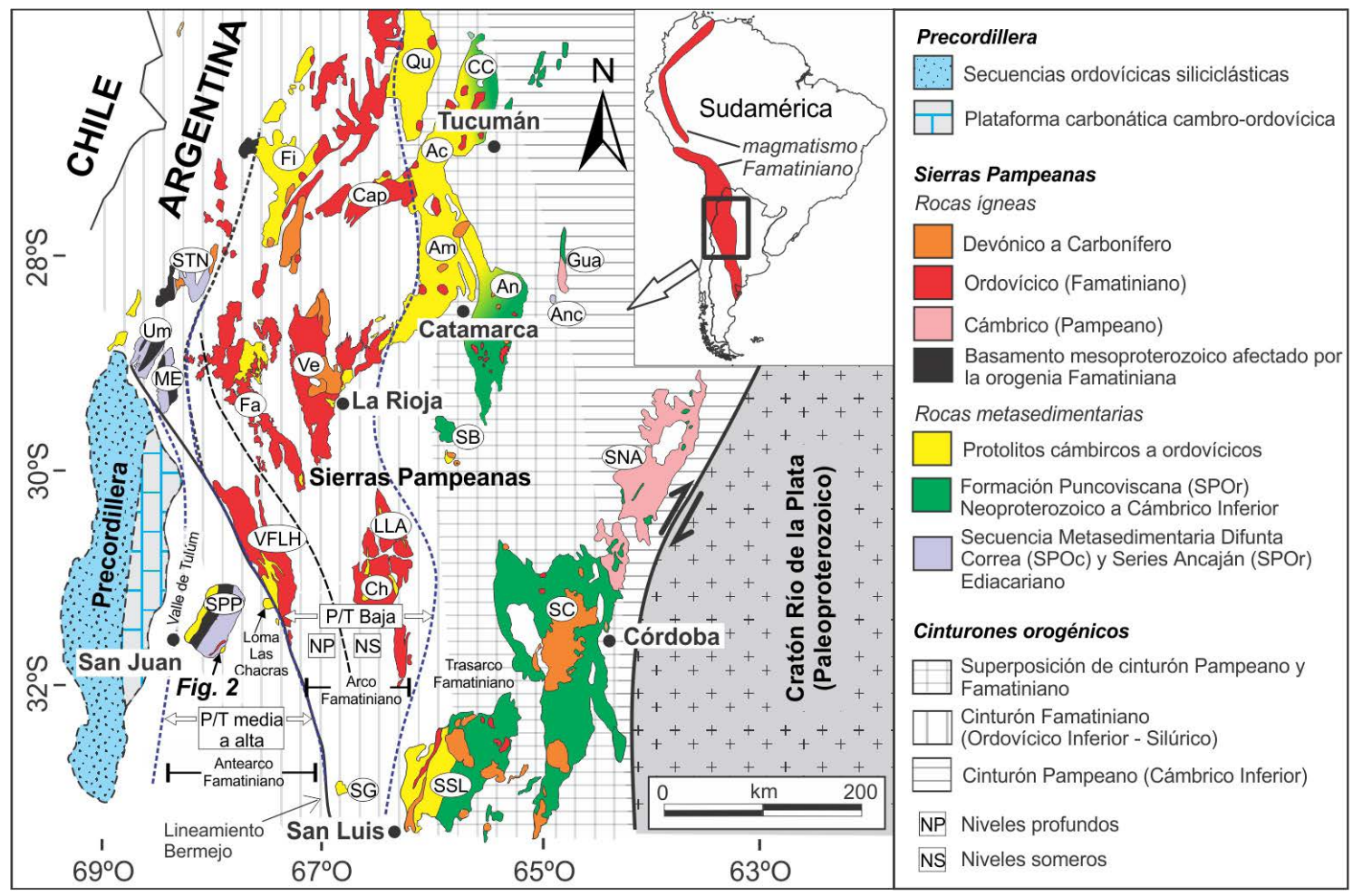

FIG. 1. Mapa geológico de las Sierras Pampeanas y Precordillera modificado de Rapela et al. (2016). Ac: Aconquija. Am: Ambato. An: Ancasti. Anc: Ancaján. CC: Cumbres Calchaquies. Cap: Capillitas. Ch: Chepes. Fa: Famatina. Fi: Fiambalá. Gua: Guasayán. ME: Maz-Espinal. LLA: Los Llanos. SB: Sierra Brava. SC: Sierras de Córdoba. SG: Sierra de El Gigante. SNA: Sierra Norte-Ambargasta. SPP: Sierra de Pie de Palo. SSL: Sierra de San Luis. STN: Sierra del Toro Negro. Um: Umango. VFLH: Valle Fértil-La Huerta. Ve: Velasco. Qu: Quilmes. 
el Ordovícico (e.g., Astini et al., 1995; Thomas y Astini, 2003; Astini y Dávila, 2004).

La Sierra de Pie de Palo (SPP) corresponde a una de las sierras más occidentales de las Sierras Pampeanas, ubicada entre la Precordillera al oeste y las rocas del arco magmático famatiniano aflorantes en la Sierra de Valle Fértil-La Huerta al este (Fig. 1). El bloque de Pie de Palo fue originalmente interpretado como el basamento de la plataforma carbonática de Precordillera formando un terreno compuesto denominado Cuyania (Ramos, 2004 y referencias allí citadas). Esta idea implicaba que el bloque de Pie de Palo habría formado parte de la placa inferior durante la subducción famatiniana dirigida hacia el este. Sin embargo estudios posteriores indican que el bloque de Pie de Palo habría formado parte del margen SO de Gondwana desde el Cámbrico Inferior y que correspondería a la placa superior durante la subducción Ordovícica, formando parte del antearco famatiniano (e.g., Mulcahy et al., 2011; Baldo et al., 2012; Ramacciotti et al., 2014, 2017, 2018). En este contexto, por su litología y ubicación, la SPP constituye una pieza clave en el rompecabezas geotectónico del orógeno Famatiniano. En ella se encuentran rocas de edad grenvilliana (ca. 1.000-1.300 Ma; McDonough et al., 1993; Rapela et al., 2010 y referencias allí citadas), una cubierta metasedimentaria ediacarense de afinidad lauréntica (Galindo et al., 2004; Ramacciotti et al., 2015a, b; Rapela et al., 2016) y rocas ígneas y metamórficas ordovícicas (Casquet et al., 2001; Mulcahy et al., 2011; Baldo et al., 2012) que contribuyen al entendimiento de procesos orogénicos ocurridos entre el Mesoproterozoico y el Paleozoico inferior en este sector de Sudamérica.

La evolución tectono-metamórfica de la SPP durante la orogenia Famatiniana es aún poco conocida, ya que la mayoría de los trabajos previos se han concentrado en estimar las condiciones de presión y temperatura $(P-T)$ del clímax metamórfico con métodos termobarométricos convencionales (Casquet et al., 2001; Mulcahy et al., 2011, van Staal et al., 2011). Además no se ha realizado, previo a este trabajo, un análisis comparativo del metamorfismo dentro del antearco en relación con la tectónica del mismo. En esta contribución se establecen las condiciones y gradiente $P$ - $T$ de un esquisto estaurolítico (metapelita) ubicado al sureste de la SPP mediante el modelado de equilibrio de fases minerales (pseudosecciones; Powell y Holland, 2008). Estos datos son integrados con los obtenidos por otros autores con la finalidad de establecer la evolución tectonotérmica del antearco famatiniano en este sector de las Sierras Pampeanas.

\section{Marco geológico}

\subsection{Orogenia Famatiniana}

Esta orogenia fue definida por Aceñolaza y Toselli (1973) en el noroeste Argentino para designar a las secuencias comprendidas entre la discordancia Tilcárica, atribuida a la orogenia Pampeana (Cámbrico Inferior), y el Devónico Superior. El orógeno Famatiniano comprende un extensa área que abarca desde la Patagonia hasta Venezuela (Ramos, 2018), y está representado en las Sierras Pampeanas por un arco magmático de composición máfica a félsica de edad ca. 470 Ma (e.g., Pankhurst et al., 1998, 2000; Dahlquist et al., 2008, 2012; Ducea et al., 2010, 2017; Otamendi et al., 2017). Se reconoce además, un dominio de basamento esencialmente proterozoico al oeste del arco magmático (ver más abajo) en el que se ubica la SPP, objeto de este trabajo, y una extensa región al este del mismo que se extiende hasta las Sierras de Córdoba (trasarco famatiniano) constituida mayoritariamente por rocas metasedimentarias prefamatinianas (Cámbrico Inferior) (Fig.1). El metamorfismo regional famatiniano en las Sierras Pampeanas se reconoce en los tres dominios mencionados con edades entre $c a .480$ y 440 Ma (e.g., Casquet et al., 2001; Gallien et al., 2010; Larrovere et al., 2011; Mulcahy et al., 2014) y condiciones $P-T$ variables de acuerdo con la posición respecto del arco magmático (Otamendi et al., 2008; Fig. 1). La región del arco magmático y el trasarco se caracterizan por un metamorfismo de bajo gradiente $P / T$ y trayectorias antihorarias con presiones menores a 8 kbar y temperaturas de hasta ca. $900^{\circ} \mathrm{C}$, encontrándose la zona de mayor profundidad en las Sierras de Cerro Toro y Valle Fértil, y la zona más somera en las sierras de Famatina, Chepes y Velasco (Dahlquist y Baldo, 1996; Hauzenberger et al., 2001; Büttner et al., 2005; Dahlquist et al., 2005; Murra y Baldo, 2006; Steenken et al., 2006; Delpino et al., 2007; Castro de Machuca et al., 2008; Otamendi et al., 2008; Gallien et al., 2010, 2012; Larrovere et al., 2011, Alasino et al., 2014). En el dominio al oeste del arco magmático famatiniano (Sierra de Pie de Palo, Loma de Las Chacras) es donde se desarrolla un metamorfismo de mayor 
presión alcanzando valores de hasta 13 kbar (Baldo et al., 1998; Casquet et al., 2001; van Staal et al., 2011; Mulcahy et al., 2011, 2014).

\subsection{Geología de la Sierra de Pie de Palo}

La SPP se encuentra formada por un complejo de corrimientos imbricados de vergencia oeste (Casquet et al., 2001; Mulcahy et al., 2011) constituido por láminas tectónicas que pueden contener más de una unidad litoestratigráfica. Sobre la base de los trabajos previos mencionados y de nuestras propias observaciones (Ramacciotti et al., 2015a, b; Ramacciotti, 2016) enumeramos a continuación las principales unidades o láminas tectónicas ordenadas de abajo hacia arriba estructuralmente, y de oeste a este a través de la sierra (Fig. 2): Unidad Caucete (UC), Unidad Complejo de Pie de Palo (UCPP), Unidad Quebrada Seca (UQS) Unidad La Loma (ULL), Unidad Vallecito (UV) Unidad El Indio (UEI) y Unidad Nikizanga (UN). La litoestratigrafía de la SPP ha sido descrita por Ramaciotti et al. (2015a y b).

La UC, ubicada por bajo del corrimiento Pirquitas (van Staal et al., 2011 y referencias allí citadas), está formada por el Grupo Caucete, una serie metasedimentaria compuesta principalmente de rocas carbonáticas y siliciclásticas con una edad de sedimentación neoproterozoica a cámbrica (Galindo et al., 2004; Naipauer et al., 2010). La UCPP se encuentra entre los corrimientos Pirquitas y Duraznos y está compuesta principalmente por rocas máficas y ultramáficas interpretadas como un complejo ofiolítico mesoproterozoico grenvilliano (e.g., Vujovich y Kay, 1998). La UQS, aflora entre los corrimientos Duraznos y Morales (Ramacciotti, 2016) y corresponde a un basamento de difícil acceso y poco conocido, compuesto principalmente por migmatitas, ortogneises, esquistos y cuarcitas mesoproterozoicas y una cubierta de mármoles y anfibolitas neoproterozoicas equivalente a la Secuencia Metasedimentaria Difunta Correa (SMDC; v. abajo) (Casquet et al., 2001; Vujovich et al., 2004; Mulcahy et al., 2011). La edad de las rocas ígneas mesoproterozoicas alojadas en la UCPP y la UQS varían entre $c a .1 .030$ y $1.280 \mathrm{Ma}$ (Vujovich et al., 2004; Morata et al., 2010; Rapela et al., 2010; Mulcahy et al., 2011; Garber et al., 2014). Además, dentro de la UQS se encuentran alojados ortogneises tipo "A" con una edad de cristalización de $c a$. $775 \mathrm{Ma}$ interpretados como evidencia de la ruptura temprana del supercontinente Rodinia (Baldo et al., 2006). La ULL se extiende entre el cabalgamiento de Morales y la faja de cizalla normal Vallecito y está compuesta principalmente por cuarcitas oscuras pertenecientes a la unidad litoestratigráfica $\mathrm{La}$ Loma (Ramacciotti et al. 2015a y b) dentro de la SMDC. La SMDC está constituida por una compleja unidad metasedimentaria de plataforma continental, depositada en el Ediacariano inferior, compuesta por rocas metasiliciclásticas y metacarbonáticas, descrita y datada por Baldo et al. (1998), Rapela et al. (2005), Ramacciotti et al. (2015a, b). La UV se encuentra entre la zona de cizalla Vallecito y el corrimiento El Indio y se compone principalmente de mármoles pertenecientes a la SMDC mientras que la UEI aflora entre el corrimiento homónimo y la zona de cizalla normal Nikizanga y se compone de rocas metasiliciclásticas además de abundantes intrusiones graníticas ordovícicas alojadas en dicho cabalgamiento (e.g., Granito El Indio; Baldo et al., 2012). Al este de la faja de cizalla extensional Nikizanga aflora la UN formada por el Grupo Nikizanga y la SMDC. El Grupo Nikizanga está formado por rocas metamórficas de bajo grado (mármoles grafíticos, cuarcitas, y filitas) cuyos protolitos sedimentarios se depositaron en el Cámbrico (Ramacciotti et al., 2018). Esta secuencia ha sido correlacionada sobre la base de la composición isotópica de $\mathrm{Sr}$ de mármoles y edades $\mathrm{U}-\mathrm{Pb}$ en circones detríticos con el Grupo Caucete y con el Grupo Mesón del noroeste de Argentina, y ha sido interpretada como una depositación en una plataforma continental perteneciente al margen suroccidental de Gondwana (Ramacciotti et al., 2018).

El metamorfismo que afecta a las rocas más antiguas de la sierra es atribuido a la orogenia grenvilliana ( $c a .1 .000-1.250 \mathrm{Ma}$ ). Las cubiertas sedimentarias neoproterozoicas-cámbricas (SMDC, Grupo Caucete y Grupo Nikizanga) muestran un único metamorfismo regional consecuencia de la orogénesis Famatiniana. El pico térmico, próximo al de máximo enterramiento vía infracorrimientos (underthrusting), se ha datado entre los $c a$. 460-470 Ma (Casquet et al., 2001; Vujovich et al., 2004; Mulcahy et al., 2011; Garber et al., 2014). Este evento fue seguido de un metamorfismo dinámico localizado en fajas de cizalla de cinemática variable, aún poco conocido, hacia los ca. 440-415 Ma (Mulcahy et al., 2011; Garber et al., 2014). El metamorfismo grenvilliano fue interpretado a partir de migmatitas miloníticas del basamento mesoproterozoico como un evento 


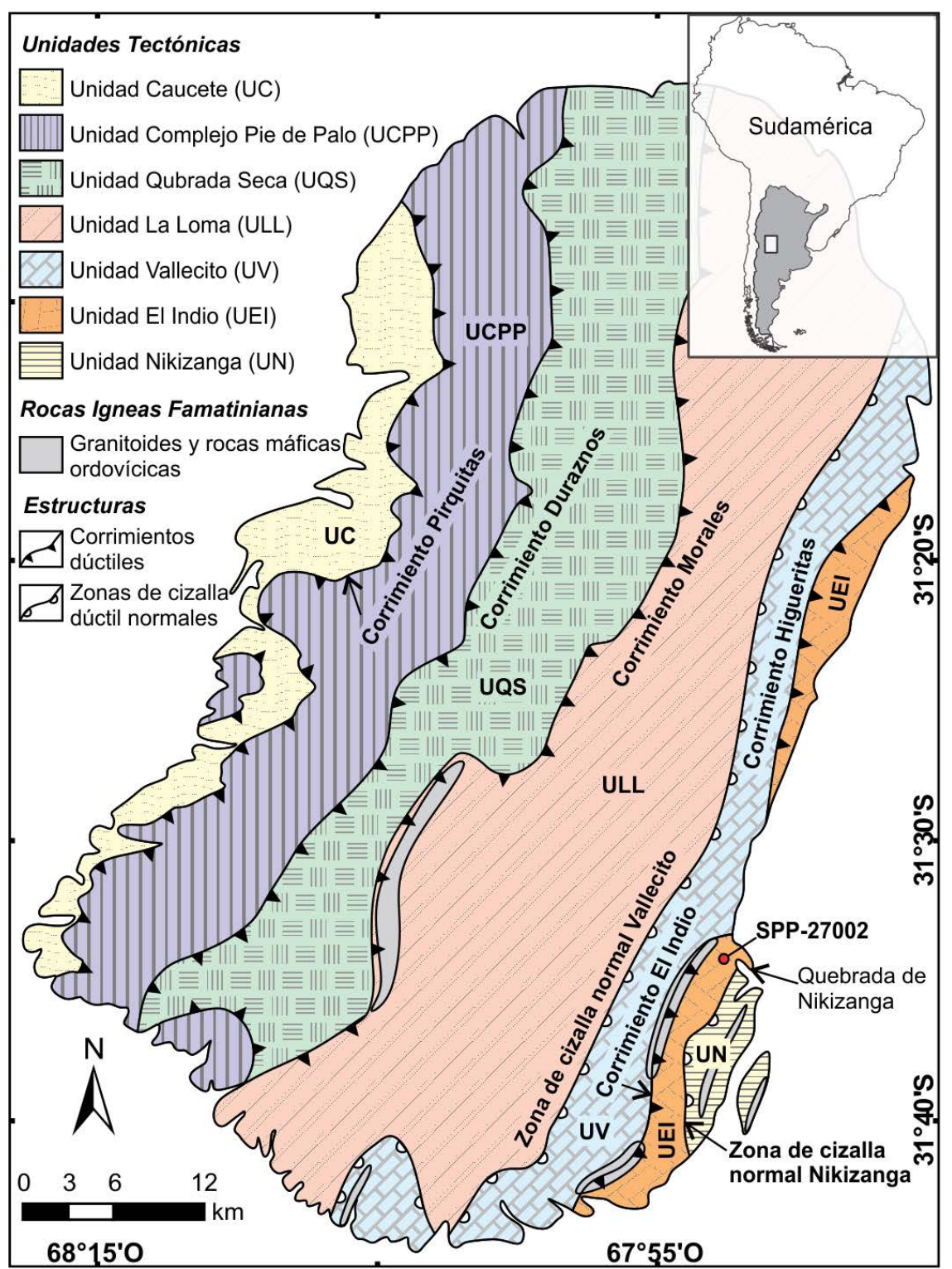

FIG. 2. Mapa geológico simplificado de la Sierra de Pie de Palo (basado en Casquet et al., 2001; Mulcahy et al., 2011; Ramacciotti et al., 2015b) mostrando las principales estructuras, unidades tectónicas y la ubicación de la muestra estudiada (SPP-27002).

de presión media $(6,9 \pm 0,4 \mathrm{kbar})$ y alta temperatura $\left(790 \pm 17^{\circ} \mathrm{C}\right.$; Casquet et al., 2001). El metamorfismo famatiniano fue caracterizado en el sector occidental de la SPP como un evento de trayectoria $P-T$ horaria con condiciones de hasta $13 \pm 1$ kbar y $600 \pm 50^{\circ} \mathrm{C}$ (Baldo et al., 1998; Casquet et al., 2001). Van Staal et al. (2011) proponen igualmente una trayectoria horaria para el metamorfismo famatiniano con un pico bárico de $c a .13$ kbar y $450{ }^{\circ} \mathrm{C}$. Los trabajos mencionados se focalizaron en el sector occidental y central de la SPP, en tanto que en el sector oriental se dispone de descripciones petrográficas y mineralógicas detalladas de diversos tipos de rocas, pero con estimaciones termobarométricas poco precisas (Seia, 1996). En este trabajo estimamos las condiciones $P-T$ de la Unidad El Indio en el sector más oriental de la sierra empleando métodos termobarométricos más precisos (pseudosecciones). 


\section{Petrografía e interpretación textural}

El análisis de las condiciones metamórficas realizado en este trabajo se llevó a cabo en esquistos estaurolíticos de la Unidad tectónica El Indio ubicados en la quebrada de Nikizanga (Fig. 2). Tal como se expone en esta sección y en la siguiente estas rocas poseen una gran cantidad de información textural, como así también una composición química y mineral que facilitan el modelado de equilibrio de fases. Los esquistos estaurolíticos pertenecen a la SMDC y afloran esporádicamente en niveles de unos $5 \mathrm{~m}$ de espesor, intercalados con esquistos con muscovita y granate, y esquistos con granate, muscovita y anfíbol (Fig. 3). La alternancia de niveles de diferentes composiciones, representa el registro relíctico de la estratificación $\left(\mathrm{S}_{0}\right)$. Esta superficie ha sido sobreimpresa por una foliación $\left(\mathrm{S}_{1}\right)$ registrada dentro y fuera de los porfiroblastos (ver abajo), la cual representa la foliación principal de la unidad, con una orientación aproximada NNE-SSO en el sector suroriental de la sierra.

El estudio se focaliza en una muestra de estos esquistos estaurolíticos (SPP-27002; 31 34'46" S-67 $52^{\prime} 51^{\prime \prime O}$ ). La asociación mineral está compuesta de estaurolita, granate, biotita, muscovita, plagioclasa, cuarzo, ilmenita, rutilo, apatita y circón. La roca muestra una única foliación $\mathrm{S}_{1}$, definida en una matriz de cuarzo, muscovita y plagioclasa, sobre la que crecen porfiroblastos de biotita, estaurolita y granate, los dos primeros sin orientación preferencial y a menudo cortando la $S_{1}$. En los tres casos, los porfiroblastos crecen sobre la $S_{1}$ atrapando inclusiones principalmente de cuarzo, que definen una foliación interna $(\mathrm{Si})$ recta y continua con la foliación externa $\left(\mathrm{Se}=\mathrm{S}_{1}\right)$ que se curva a su alrededor (Fig. 4A). También hay inclusiones de ilmenita y rutilo, por lo general concordantes con la $\mathrm{Si}$ aunque a veces están cruzadas (Fig. 4B). Es destacable la presencia de inclusiones de granate y biotita en la estaurolita, que representan una etapa temprana de cristalización de estos minerales (Fig. 4C).

El granate (Grt) registra dos variedades texturales. El Grt ${ }_{1}$, el más abundante, presenta el patrón orientado ya mencionado de inclusiones rectilíneas de cuarzo $(<55 \mathrm{~mm})$ acompañadas de escasas inclusiones de cristales subhedrales de ilmenita. Tiene formas subhedrales y tamaño de $c a .2 \mathrm{~mm}$. El Grt ${ }_{2}$ aparece como bordes de sobrecrecimientos en el Grt ${ }_{1} \mathrm{o}$ como pequeños cristales individuales en la matriz (Fig. 4A-C). Tiene formas anhedrales a localmente subhedrales, con dimensiones menores a $0,2 \mathrm{~mm}$, como recrecimiento, y tamaños $<1 \mathrm{~mm}$ en los granos individuales. Presenta inclusiones aciculares de rutilo e ilmenita, además de cuarzo con dimensiones superiores a las registradas en el $\mathrm{Grt}_{1}(c a .100 \mathrm{~mm})$, similares al tamaño de grano de la matriz, las cuales definen trayectorias curvas. El contacto entre los granates $\mathrm{Grt}_{2}$ y Grt ${ }_{1}$ suele ser irregular, presentando en algunos sectores límites engolfados, lo que indicaría que el Grt ${ }_{1}$ es parcialmente reabsorbido previo o durante el crecimiento del $\mathrm{Grt}_{2}$.
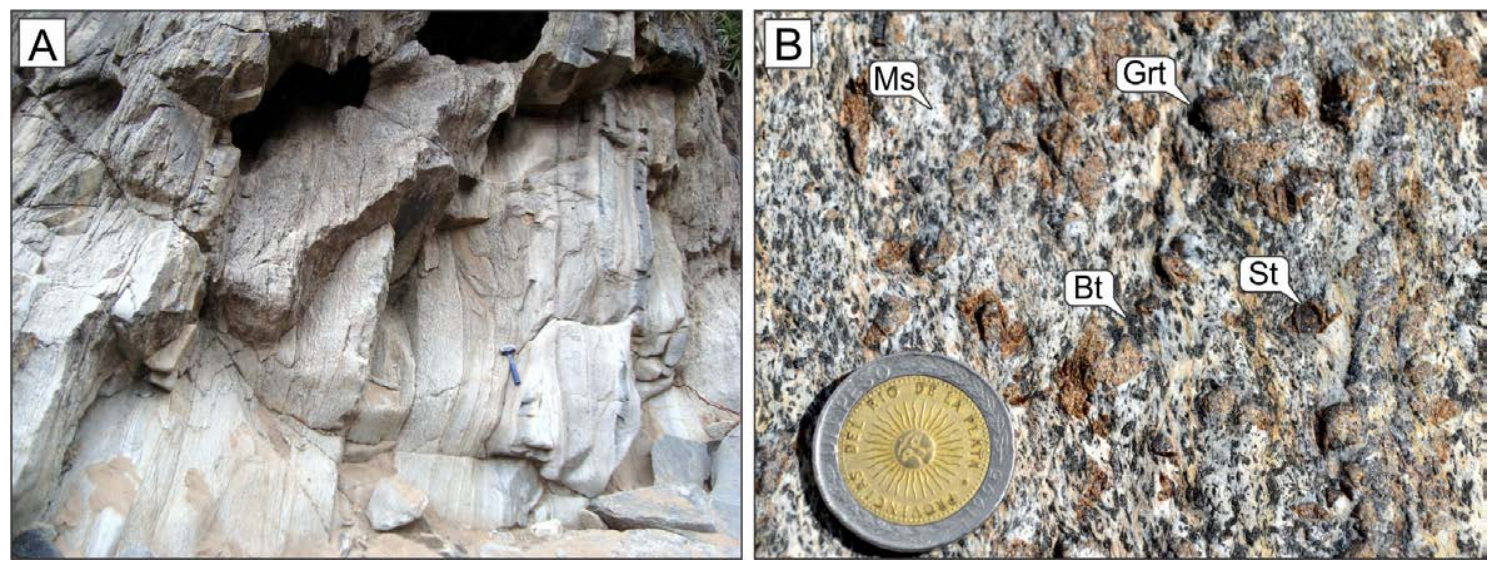

FIG. 3. Afloramiento de los esquistos estaurolíticos. A. Intercalaciones de esquistos estaurolíticos con esquistos con granate, anfíbol y muscovita, preservando el bandeado composicional $\mathrm{S}_{0}$. B. Imagen de detalle de los esquistos estaurolíticos, en la que pueden apreciarse los porfiroblastos de granate, estaurolita y biotita y abundante muscovita. La moneda mide 2,2 cm. 

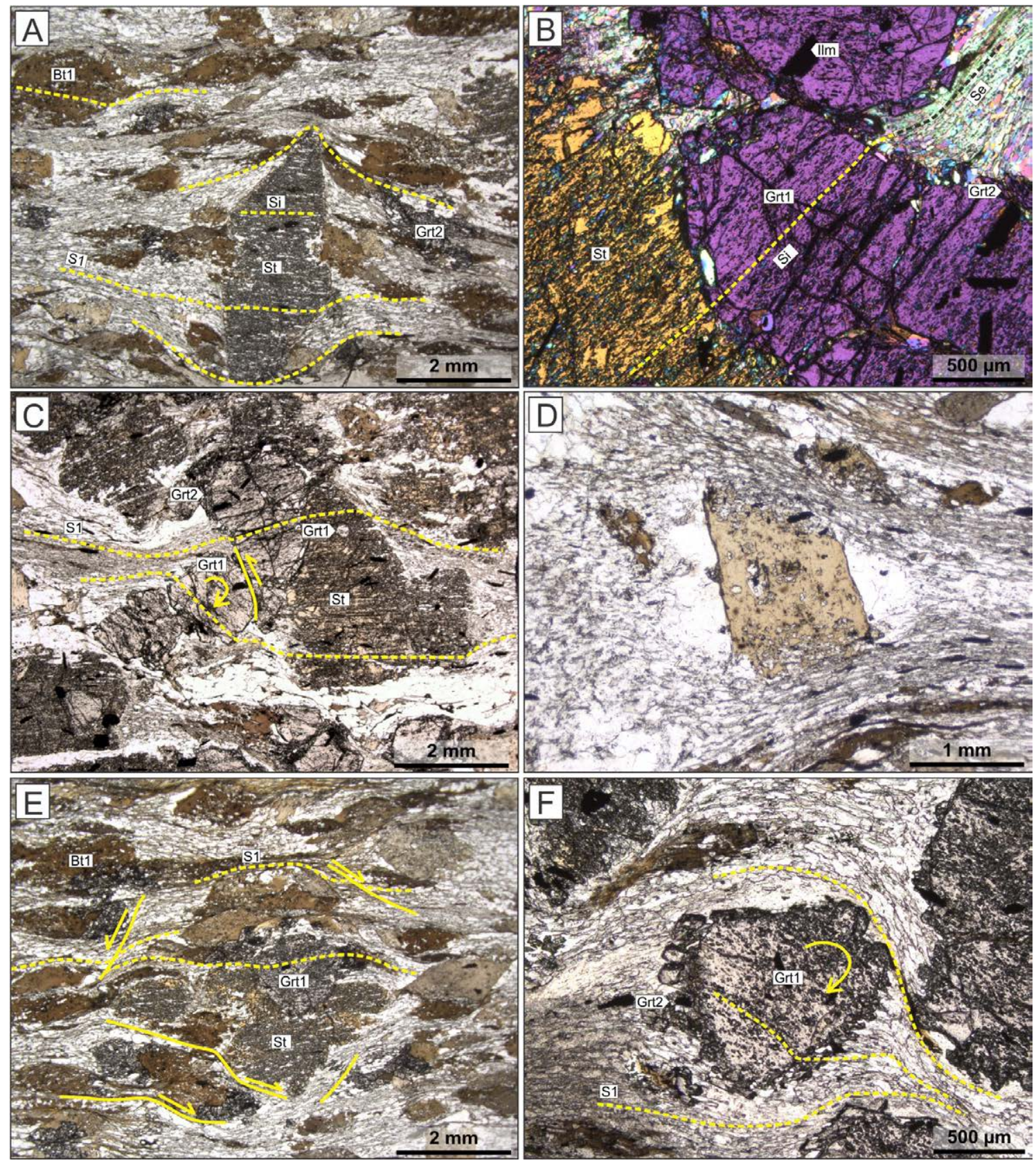

FIG. 4. Fotomicrografías del esquisto estaurolítico SPP-27002. A. Textura general porfiroblástica donde pueden verse las foliaciones internas $(\mathrm{Si})$ y externas $\left(\mathrm{Se}=\mathrm{S}_{1}\right)$ y las distintas generaciones de granate $\left(\mathrm{Grt}_{1}\right.$ y $\left.\mathrm{Grt}_{2}\right)$. B. Fotomicrografía tomada con placa de yeso mostrando la continuidad de la $\mathrm{Si}$ al pasar de la estaurolita al Grt sugiriendo que ambos minerales son paragenéticos. C. Microbandas de cizallas conjugadas y rotación de porfiroblastos de Grt. D. Rotación a paralelismo de la Bt desarrollando sobras de deformación. E-F. Microbandas de cizallas conjugadas y rotación de porfiroblastos de Grt $_{1}$. 
Las estaurolitas ( $\mathrm{St}$ ) forman poiquiloblastos euhedrales que pueden alcanzar los $10 \mathrm{~mm}$ de largo y suelen encontrarse en contacto con el Grt ${ }_{1}$, mostrando una continuidad de la foliación interna al pasar de un mineral al otro (Figs. 4A y B). Se encuentra parcialmente reemplazada en los bordes por muscovita. Por otra parte, la biotita $(\mathrm{Bt})$ se presenta en dos variedades texturales: las $\mathrm{Bt}_{1}$ corresponden a los poiquiliblastos de $c a$. 1-2 mm con inclusiones alineadas en forma rectilínea (Si) que se continúan con la foliación externa (Fig. 4A). Las $\mathrm{Bt}_{2}$ miden aproximadamente $0,5 \mathrm{~mm}$ de largo y se encuentran orientadas según Se, ubicándose mayormente en bordes de los poiquiloblastos de $\mathrm{Bt}_{1}$.

La foliación externa (Se) se encuentra afectada por una deformación co-planar tardía (respecto a Se) que genera el curvamiento de la misma en torno a los poiquilobastos, principalmente de estaurolita y $\mathrm{Grt}_{1}$ (Fig. 4A), a la vez que los cristales de $\mathrm{Bt}_{1}$ rotan hacia paralelismo con la Se y forman sombras de deformación a ambos lados de los mismos (Fig. 4D). Durante esta deformación se generan también microbandas de cizalla conjugadas (Fig. 4E), y en relación con ellas, rotaciones de cristales de Grt (Figs. 4C y F). Durante esta etapa se produce además un incremento en el tamaño de grano de la matriz.
Todas estas microestructuras son posteriores a la formación de los poiquiloblastos. El Grt ${ }_{2}$ contiene localmente inclusiones que definen una Si plegada, lo que sugiere que podría ser coetáneo con la deformación co-planar tardía.

\section{Geoquímica de roca total y química mineral}

La geoquímica de roca total de la muestra de esquisto estaurolítico (SPP-27002) fue tomada de Ramacciotti et al. (2015b). Los resultados se muestran en la tabla 1 , junto con las composiciones químicas efectivas calculadas y utilizadas en el modelado (ver abajo). La composición química de la muestra SPP27002 corresponde a una pelita de acuerdo con el diagrama de clasificación de rocas sedimentarias de Herron (1988) con $\mathrm{SiO}_{2}=59,95 \%, \mathrm{Al}_{2} \mathrm{O}_{3}=18,79 \%$ y $\mathrm{FeO} / \mathrm{MgO}=5,42$ (Ramacciotti et al., 2015b).

La composición química de los minerales se determinó en el Laboratorio de Microscopía Electrónica y Análisis por Rayos X (LAMARX) de la Universidad Nacional de Córdoba mediante una microsonda JEOL-JXA-8230. Para análisis realizados con WDS (Wavelength Dispersive X-ray Spectroscopy) se utilizó un voltaje de $15 \mathrm{kV}$ y una intensidad de corriente de $20 \mathrm{nA}$ con un haz de 5 micras de ancho, mientras

TABLA 1. GEOQUÍMICA DE ROCA TOTAL Y COMPOSICIONES EFECTIVAS UTILIZADAS EN EL MODELADO DE EQUILIBRIO DE FASES.

\begin{tabular}{cccccc}
\hline & \% Peso & Límite de Detección & $\begin{array}{c}\text { Grt1 núcleo } \\
\text { (molar) }\end{array}$ & $\begin{array}{c}\text { Grt1 borde } \\
\text { (molar) }\end{array}$ & $\begin{array}{c}\text { Grt2 } \\
(\mathbf{m o l a r})\end{array}$ \\
\hline $\mathbf{H}_{2} \mathbf{O}$ & - & - & 16,27 & 16,76 & 6,34 \\
$\mathbf{S i O}_{2}$ & 59,95 & 0,625 & 58,51 & 58,99 & 72,21 \\
$\mathbf{A l}_{2} \mathbf{O}_{3}$ & 18,79 & 0,274 & 10,80 & 10,70 & 8,23 \\
$\mathbf{C a O}$ & 1,13 & 0,061 & 1,04 & 0,93 & 1,03 \\
$\mathbf{M g O}$ & 1,93 & 0,096 & 2,81 & 2,86 & 3,35 \\
$\mathbf{F e O}$ & 10,48 & 0,129 & 7,82 & 7,14 & 5,35 \\
$\mathbf{K} \mathbf{O}$ & 3,07 & 0,017 & 1,91 & 1,97 & 2,64 \\
$\mathbf{N a} \mathbf{O}$ & 0,65 & 0,044 & 0,61 & 0,63 & 0,84 \\
$\mathbf{M n O}$ & 0,26 & 0,006 & 0,22 & 0,04 & 0,00 \\
$\mathbf{T i O}_{2}$ & 1,00 & 0,012 & - & - & - \\
$\mathbf{P}_{2} \mathbf{O}_{2}$ & 0,11 & 0,037 & - & - & - \\
$\mathbf{L O I}$ & 1,03 & - & - & $\mathbf{1 0 0 , 0 0}$ & - \\
$\mathbf{T o t a l}^{\mathbf{2}}$ & $\mathbf{9 8 , 3 9}$ & - & $\mathbf{1 0 0 , 0 0}$ & $\mathbf{1 0 0 , 0 0}$ \\
\hline
\end{tabular}

LOI: pérdida por ignición. 
que para los análisis realizados con EDS (Energy Dispersive X-ray Spectroscopy) se utilizó un voltaje de $15 \mathrm{kV}$ y un tiempo de conteo de 60 segundos. Las composiciones minerales se encuentran en la tabla 2 y en la tabla suplementaria.

Los Grt ${ }_{1}$ poseen una zonación química típica de un progrado metamórfico con una disminución del contenido de espesartina (Sps), y aumento de almandino (Alm) y piropo (Prp) desde el núcleo hacia los bordes, mientras que la grosularia (Grs) se mantiene sin demasiada variación (Fig. 5A-D). Los núcleos de estos granates tienen una composición promedio $\mathrm{Alm}=0,71, \mathrm{Sps}=0,14, \mathrm{Grs}=0,11, \mathrm{y}$ $\operatorname{Prp}=0,04$; en tanto que los bordes del mismo tienen los siguientes valores: $\mathrm{Alm}=0,79, \mathrm{Sps}=0,04$, Grs $=0,08$, y Prp=0,09. El Grt ${ }_{2}$ está compuesto por $\mathrm{Alm}=0,72$, Sps $=0,01, \mathrm{Grs}=0,15$, y $\operatorname{Prp}=0,12$. Los porfiroblastos de estaurolita no poseen variaciones composicionales significativas a lo largo de los cristales con valores de $\mathrm{X}_{\mathrm{Fe}}(\mathrm{Fe} / \mathrm{Fe}+\mathrm{Mg})$ entre $0,79 \mathrm{y}$ 0,82 , con un promedio de $0,80(n=48 ;$ Fig. $5 E$ y F $)$. Las biotitas poseen valores de $\mathrm{X}_{\mathrm{Fe}}$ entre $0,49 \mathrm{y}$ $0,43, \mathrm{Al}^{\text {total }}$ (apfu) entre 3,39 y 3,58 , en tanto que las muscovitas tienen valores de $\mathrm{X}_{\mathrm{Fe}}=0,38-0,44 \mathrm{y}$ $\mathrm{Al}^{\text {total }}(\mathrm{apfu})=5,47-5,58$ (Fig. 6), y la plagioclasa es de composición andesina $\left(\mathrm{Ab}_{58}\right)$.

\section{Modelado de equilibrio de fases minerales}

Con el objeto de reconstruir la trayectoria $P-T$ del metamorfismo registrado en estos esquistos con estaurolita, se realizó un análisis del equilibrio mineral mediante la construcción de pseudosecciones $P-T$. Esta herramienta nos permite reproducir diferentes etapas dentro de la trayectoria $P-T$. Sin embargo, la composición química global en cada etapa dependería de la proporción y composición de los minerales que participan del equilibrio y del posible fraccionamiento composicional, como ocurre en minerales zonados (e.g., granate), los cuales definen un volumen o composición global efectiva (e.g., Stüwe, 1997). En este sentido, la composición global seleccionada corresponde a la de una muestra representativa de estos esquistos (SPP-27002; Ramaciotti et al., 2015b).

Con el objetivo de obtener una trayectoria $P-T$ se han modelado tres etapas del progrado metamórfico: 1) crecimiento temprano del núcleo del Grt 2) crecimiento en el pico térmico del borde del $\mathrm{Grt}_{1}$, junto a poiquiloblastos de estaurolita y $\mathrm{Bt}_{2} ; \mathrm{y}$ 3) crecimiento del $\mathrm{Grt}_{2}$. Durante las etapas 1 y 2 , el contenido de Mn en la composición global ha sido determinante para el crecimiento y estabilización de granate. Sin embargo, la composición química de los Grt ${ }_{2}$ sugiere un fuerte fraccionamiento de este elemento en el $\mathrm{Grt}_{1}$, por lo que el Mn no sería un elemento esencial en la composición global efectiva. Por esta razón, las pseudosecciones fueron construidas utilizando dos sistemas químicos: las etapas 1 y 2 fueron analizadas en el sistema MnNCKFMASH ( $\mathrm{MnO}-\mathrm{Na}_{2} \mathrm{O}-\mathrm{CaO}-\mathrm{K}_{2} \mathrm{O}-\mathrm{FeO}-$ $\mathrm{MgO}-\mathrm{Al}_{2} \mathrm{O}_{3}-\mathrm{SiO}_{2}-\mathrm{H}_{2} \mathrm{O}$ ), mientras que para la etapa 3 se utilizó el sistema NCKFMASH $\left(\mathrm{Na}_{2} \mathrm{O}-\mathrm{CaO}-\right.$ $\mathrm{K}_{2} \mathrm{O}-\mathrm{FeO}-\mathrm{MgO}-\mathrm{Al}_{2} \mathrm{O}_{3}-\mathrm{SiO}_{2}-\mathrm{H}_{2} \mathrm{O}$ ) (ver lista de composiciones en la Tabla 1 ).

Debido a que el efecto del $\mathrm{Fe}^{3+}$ y el Ti no fueron considerados, se realizó una corrección por presencia de ilmenita, ya que esta secuestra Fe y sobrestima la concentración de este elemento en la composición global. Para minimizar este efecto, se sustrajo una cantidad molar de $\mathrm{FeO}$ equivalente a la cantidad molar de $\mathrm{TiO}_{2}$ contenida en la composición global, asumiendo una distribución ideal en la estequiometria de la ilmenita $\left(1 \mathrm{TiO}_{2}: 1 \mathrm{FeO}\right)$. De forma similar, la presencia de apatita en la asociación mineral sugiere una sobrestimación del contenido de $\mathrm{CaO}$, el cual está alojado en este mineral y no se encuentra disponible en el volumen de equilibrio, ya que no existen modelos composicionales adecuados para minerales con fósforo. Por esta razón, se realizó una corrección del calcio, quitando una cantidad molar equivalente a la proporción $5 \mathrm{CaO}: 1.5 \mathrm{P}_{2} \mathrm{O}_{3}$ en apatita.

Para la construcción de pseudosecciones se utilizó el programa THERMOCALC v3.33 (Powell y Holland, 1988) con la base de datos internamente consistente ds55, propuesta por Holland y Powell (1998; actualizada en noviembre de 2003). Los minerales y modelos de actividad-composición utilizados fueron: granate (White et al., 2005; 2007), biotita (Mahar et al., 1997; Powell y Holland, 1999; White et al., 2007), estaurolita y cordierita (Mahar et al., 1997; Holland y Powell, 1998), muscovita (Coggon y Holland, 2002), clorita (Holland et al., 1998), plagioclasa y feldespato potásico (Holland y Powell, 2003). Como fases puras se consideró sillimanita, cianita, andalucita, albita, zoisita, cuarzo y agua. El contenido de agua fue ajustado de tal manera que el sistema se encuentre saturado en este componente y su actividad fue asumida como igual a 1 . 
TABLA 2. QUÍMICA MINERAL.

\begin{tabular}{|c|c|c|c|c|}
\hline \multirow{4}{*}{ 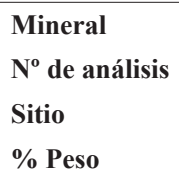 } & \multicolumn{4}{|l|}{ Granate (promedios) } \\
\hline & \multirow{3}{*}{$\begin{array}{l}6-17+65-75 \\
\text { Grt incl in St }(n=22)\end{array}$} & \multirow{3}{*}{$\begin{array}{l}\text { 24-25+54-56 } \\
\text { Grt1 núcleo }(n=5)\end{array}$} & \multirow{3}{*}{$\begin{array}{l}18,20,29,30+61-64 \\
\text { Grt1 borde }(n=8)\end{array}$} & \multirow{3}{*}{$\begin{array}{l}31,32+45-49 \\
\text { Grt } 2(n=7)\end{array}$} \\
\hline & & & & \\
\hline & & & & \\
\hline $\mathrm{SiO}_{2}$ & 36,40 & 36,30 & 36,20 & 36,82 \\
\hline $\mathrm{TiO}_{2}$ & 0,05 & 0,05 & 0,02 & 0,06 \\
\hline $\mathrm{Al}_{2} \mathrm{O}_{3}$ & 21,83 & 21,78 & 21,86 & 22,10 \\
\hline $\mathrm{Cr}_{2} \mathrm{O}_{3}$ & 0,00 & 0,01 & 0,02 & 0,01 \\
\hline $\mathrm{FeO}$ & 34,33 & 31,17 & 34,83 & 32,29 \\
\hline $\mathrm{MnO}$ & 1,86 & 5,68 & 1,71 & 0,47 \\
\hline $\mathrm{MgO}$ & 2,16 & 1,16 & 2,08 & 2,58 \\
\hline $\mathrm{CaO}$ & 3,11 & 3,78 & 2,90 & 5,64 \\
\hline Total & 99,75 & 99,94 & 99,61 & $\mathbf{9 9 , 9 7}$ \\
\hline \multicolumn{5}{|c|}{ apfu (24 oxígenos) } \\
\hline $\mathrm{Si}$ & 5,89 & 5,89 & 5,88 & 5,89 \\
\hline $\mathrm{Ti}$ & 0,01 & 0,01 & 0,00 & 0,01 \\
\hline $\mathrm{Al}$ & 4,16 & 4,16 & 4,18 & 4,16 \\
\hline $\mathrm{Cr}$ & 0,00 & 0,00 & 0,00 & 0,00 \\
\hline $\mathrm{Fe}^{2+}$ & 4,65 & 4,23 & 4,73 & 4,32 \\
\hline $\mathrm{Mn}$ & 0,25 & 0,78 & 0,23 & 0,06 \\
\hline $\mathrm{Mg}$ & 0,52 & 0,28 & 0,50 & 0,61 \\
\hline $\mathrm{Ca}$ & 0,54 & 0,66 & 0,50 & 0,97 \\
\hline Suma & 16,02 & 16,02 & 16,03 & 16,02 \\
\hline Xalm & 0,78 & 0,71 & 0,79 & 0,72 \\
\hline Xspss & 0,04 & 0,13 & 0,04 & 0,01 \\
\hline Xgro & 0,09 & 0,11 & 0,08 & 0,16 \\
\hline Xpy & 0,09 & 0,05 & 0,08 & 0,10 \\
\hline
\end{tabular}

\begin{tabular}{|c|c|c|c|}
\hline \multicolumn{2}{|c|}{$\begin{array}{ll}\text { Estaurolita } & \\
\% \text { Peso } & \text { Prom. }(n=48)\end{array}$} & \multirow{2}{*}{$\begin{array}{l}\text { Plagioclasa } \\
\mathbf{N}^{0} \text { de análisis } \\
\% \text { Peso }\end{array}$} & \multirow[t]{2}{*}{ Pl-156 } \\
\hline \multirow{2}{*}{$\begin{array}{l}\mathrm{SiO}_{2} \\
\mathrm{TiO}_{2}\end{array}$} & 26,94 & & \\
\hline & 0,45 & $\mathrm{SiO}_{2}$ & 72,95 \\
\hline $\mathrm{Al}_{2} \mathrm{O}_{3}$ & 55,83 & $\mathrm{TiO}_{2}$ & 0,00 \\
\hline $\mathrm{Cr}_{2} \mathrm{O}_{3}$ & 0,02 & $\mathrm{Al}_{2} \mathrm{O}_{3}$ & 17,44 \\
\hline $\mathrm{FeO}$ & 13,57 & $\mathrm{FeO}$ & 0,13 \\
\hline $\mathrm{MnO}$ & 0,04 & $\mathrm{MnO}$ & 0,00 \\
\hline $\mathrm{MgO}$ & 1,90 & $\mathrm{MgO}$ & $-0,00$ \\
\hline $\mathrm{CaO}$ & 0,01 & $\mathrm{CaO}$ & 5,45 \\
\hline $\mathrm{ZnO}$ & 0,18 & $\mathrm{BaO}$ & 0,00 \\
\hline $\mathrm{Na}_{2} \mathrm{O}$ & 0,01 & $\mathrm{SrO}$ & 0,06 \\
\hline $\mathrm{K}_{2} \mathrm{O}$ & 0,01 & $\mathrm{Na}_{2} \mathrm{O}$ & 4,11 \\
\hline Total & 98,94 & $\mathrm{~K}_{2} \mathrm{O}$ & 0,01 \\
\hline \multicolumn{2}{|c|}{ apfu (46 Oxígenos) } & Total & 100,08 \\
\hline $\mathrm{Si}$ & 7,39 & apfu (32 oxígenos) & \\
\hline $\mathrm{Ti}$ & 0,09 & $\mathrm{Si}$ & 12,506 \\
\hline $\mathrm{Al}$ & 18,06 & $\mathrm{Ti}$ & 0,000 \\
\hline $\mathrm{Cr}$ & 0,00 & $\mathrm{Al}$ & 3,523 \\
\hline $\mathrm{Fe}^{2+}$ & 3,11 & $\mathrm{Fe}^{2+}$ & 0,018 \\
\hline $\mathrm{Mn}$ & 0,01 & $\mathrm{Mn}$ & 0,000 \\
\hline $\mathrm{Mg}$ & 0,78 & $\mathrm{Mg}$ & $-0,000$ \\
\hline $\mathrm{Ca}$ & 0,00 & $\mathrm{Ca}$ & 1,001 \\
\hline $\mathrm{Zn}$ & 0,04 & $\mathrm{Ba}$ & 0,000 \\
\hline $\mathrm{Na}$ & 0,01 & $\mathrm{Sr}$ & 0,006 \\
\hline K & 0,00 & $\mathrm{Na}$ & 1,366 \\
\hline Suma & 29,49 & $\mathrm{~K}$ & 0,001 \\
\hline $\mathrm{XFe}$ & 0,80 & Suma & 18,417 \\
\hline Xmg & 0,20 & $\mathrm{Ab}$ & 0,58 \\
\hline & & An & 0,42 \\
\hline & & Or & 0,00 \\
\hline
\end{tabular}




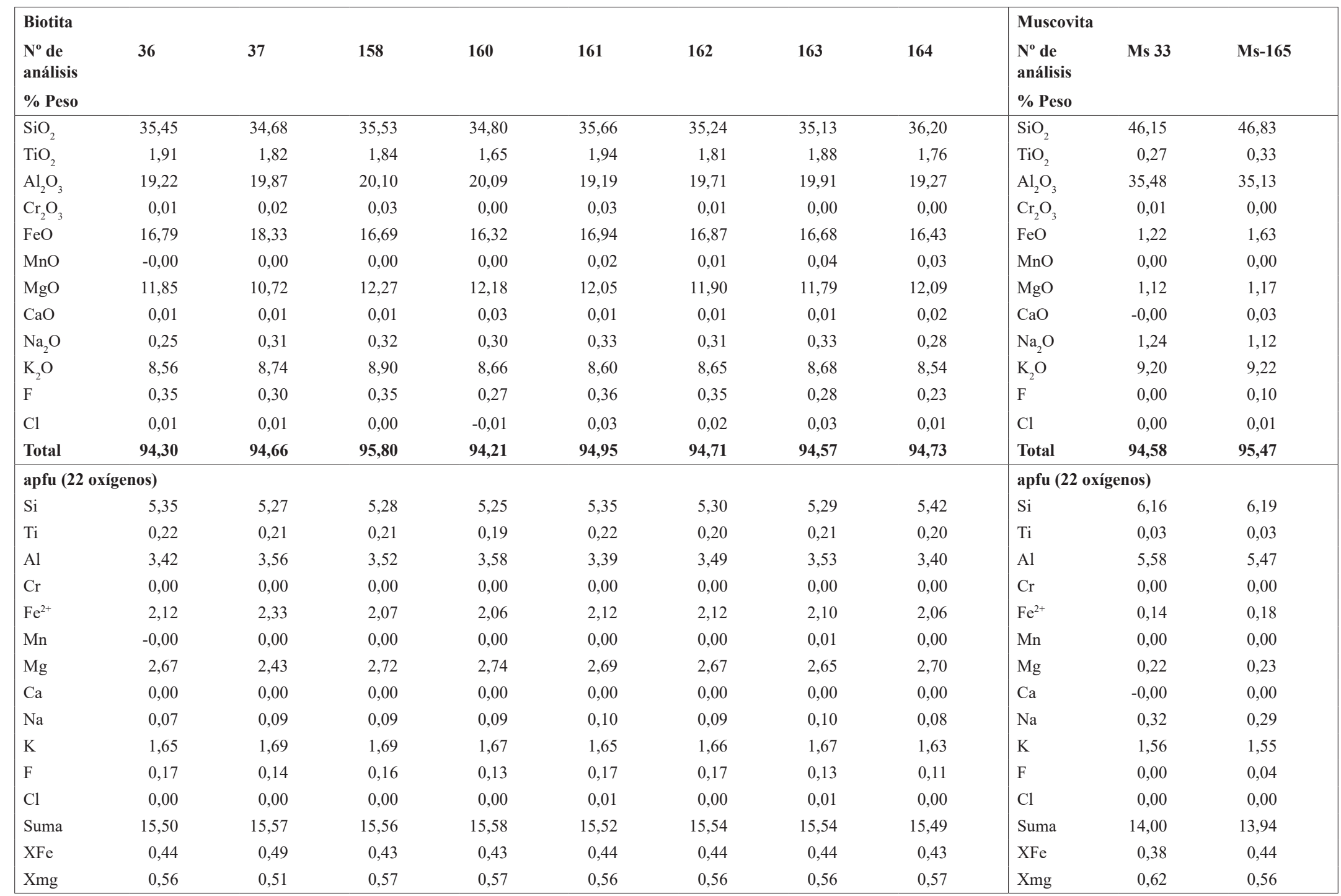



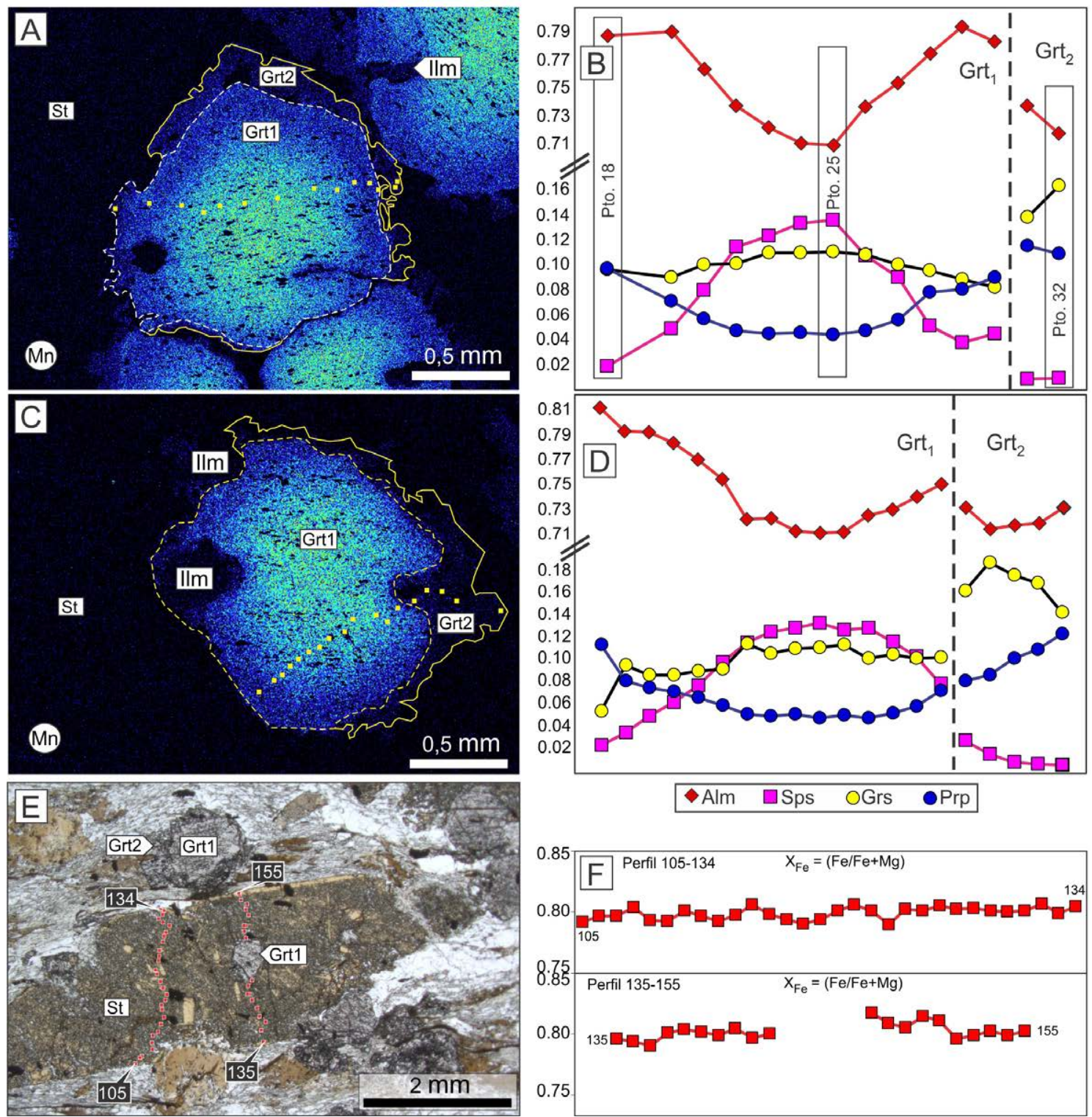

FIG. 5. Perfiles y mapas composicionales de granates y estaurolita de la muestra SPP-27002. A. Mapa composicional de Mn en granate en el cual se puede observar el paso de Grt ${ }_{1}$ a Grt ${ }_{2}$ por una disminución considerable en el contenido de Mn en este último evidenciado por colores más oscuros. Los puntos amarillos corresponden a los lugares donde se realizaron las medidas del perfil. B. Perfil composicional del granate mostrado en (A). En el Grt ${ }_{1}$ puede observarse el típico patrón de progrado metamórfico con incremento de almandino (Alm) y piropo (Prp) y disminución de espesartina (Sps) desde el núcleo al borde, en tanto que la grosularia (Grs) no muestra variaciones significativas. Al pasar al $\mathrm{Grt}_{2}$ se observa un salto composicional marcado por el incremento de Prp y Grs y disminución de Alm y Sps, llegando este último a valores cercanos a cero. C. Mapa composicional de $\mathrm{Mn}$ en granate mostrando un borde engolfado entre el $\mathrm{Grt}_{1}$ y Grt $_{2}$. El granate corresponde al mismo mostrado en la fotomicrografía de la figura 4C. D. Perfil composicional del granate mostrado en (C). El patrón es similar al descrito en (B) aunque aquí se ve un consumo de un borde de $\mathrm{Grt}_{1}$ previo al crecimiento del Grt ${ }_{2}$. E. Fotomicrografía mostrando una estaurolita y los puntos de medida de los dos perfiles realizados y mostrados en (F). F. Perfiles de $\mathrm{X}_{\mathrm{Fe}}=(\mathrm{Fe} / \mathrm{Fe}+\mathrm{Mg}) \mathrm{mostrando}$ un patrón plano con un valor medio de $\mathrm{X}_{\mathrm{Fe}}=0,80$. 


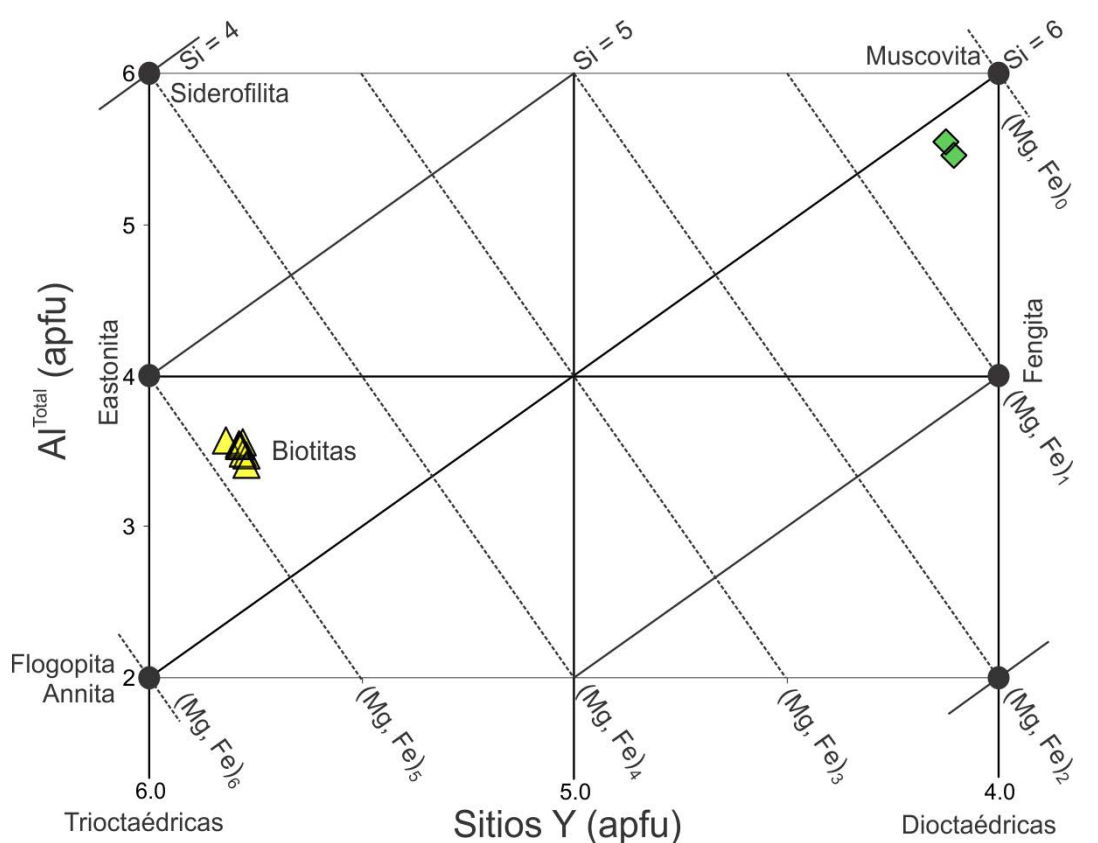

FIG. 6. Composición química de las micas de la muestra SPP-27002.

\subsection{Pseudosección $P-T$ para núcleo de Grt ${ }_{1}$}

Esta pseudosección se elaboró en el sistema MnNCKFMASH (MnO-Na ${ }_{2} \mathrm{O}-\mathrm{CaO}-\mathrm{K}_{2} \mathrm{O}-\mathrm{FeO}-\mathrm{MgO}-$ $\mathrm{Al}_{2} \mathrm{O}_{3}-\mathrm{Si}_{2} \mathrm{O}-\mathrm{H}_{2} \mathrm{O}$ ) y corresponde al momento en el que el Grt ${ }_{1}$ comienza a formarse (núcleo). En dicho momento, todos los elementos químicos habrían estado disponibles para reaccionar y es por esto que en el cálculo de la pseudosección se considera como composición efectiva a la composición global de la roca (Tabla 1). Dado que las condiciones bajo las cuales se habrían producido las reacciones serían subsólidas, se consideró un sistema saturado en $\mathrm{H}_{2} \mathrm{O}$ (5\%) para el rango $P-T$ analizado.

Los resultados se muestran en la figura 7. El cuarzo y el granate se encuentran presentes en todo el rango de $P-T$ calculado. En las condiciones de equilibrio de la parte superior del diagrama se produce la desaparición de plagioclasa. La biotita es estable en las condiciones de la mitad derecha del diagrama, en tanto que la clorita es estable en la mitad superior izquierda. La estaurolita es estable entre $c a$. 2-8 kbar y ca. $515-645^{\circ} \mathrm{C}$. La andalucita, cordierita y feldespato potásico se encuentran restringidos a bajas presiones ( $<4 \mathrm{kbar})$ y temperaturas $>520^{\circ} \mathrm{C}$ (borde inferior derecho). La sillimanita se encuentra a partir de $\operatorname{los} 585^{\circ} \mathrm{C}$, entre ca. 3 y $6 \mathrm{kbar}$, en tanto que a mayores presiones aparece la cianita (borde superior derecho). El cloritoide es estable a presiones mayores a $4 \mathrm{kbar}$ y temperaturas menores a $525^{\circ} \mathrm{C}$.

Para establecer las condiciones de presión y temperatura de equilibrio al momento de la blástesis del núcleo del $\mathrm{Grt}_{1}$ se utilizaron las isopletas calculadas a partir del análisis de dicho granate (punto 25 del perfil mostrado en la figura 5B). Las curvas se intersectan en el campo con la asociación $\mathrm{Grt}+\mathrm{Chl}+\mathrm{Ms}+\mathrm{Pl}+\mathrm{Qz}+\mathrm{H}_{2} \mathrm{O}$ (abreviaturas minerales según Whitney y Evans, 2010), limitando las condiciones de equilibrio a $3,1 \pm 0,1$ kbar y $516 \pm 1^{\circ} \mathrm{C}$ (área naranja en la figura 7).

\subsection{Pseudosección $P$ - $T$ para borde de Grt}

Esta pseudosección se elaboró en el sistema MnNCKFMASH $\left(\mathrm{MnO}-\mathrm{Na}_{2} \mathrm{O}-\mathrm{CaO}-\mathrm{K}_{2} \mathrm{O}-\mathrm{FeO}-\right.$ $\mathrm{MgO}-\mathrm{Al}_{2} \mathrm{O}_{3}-\mathrm{Si}_{2} \mathrm{O}-\mathrm{H}_{2} \mathrm{O}$ ). A medida que el $\mathrm{Grt}_{1}$ continúa creciendo, la composición efectiva va cambiando dado que los elementos capturados por el núcleo de Grt ${ }_{1}$ no se encuentran disponibles para las reacciones. Por esta razón, es necesario quitar el núcleo del Grt ${ }_{1}$ y recalcular la composición 


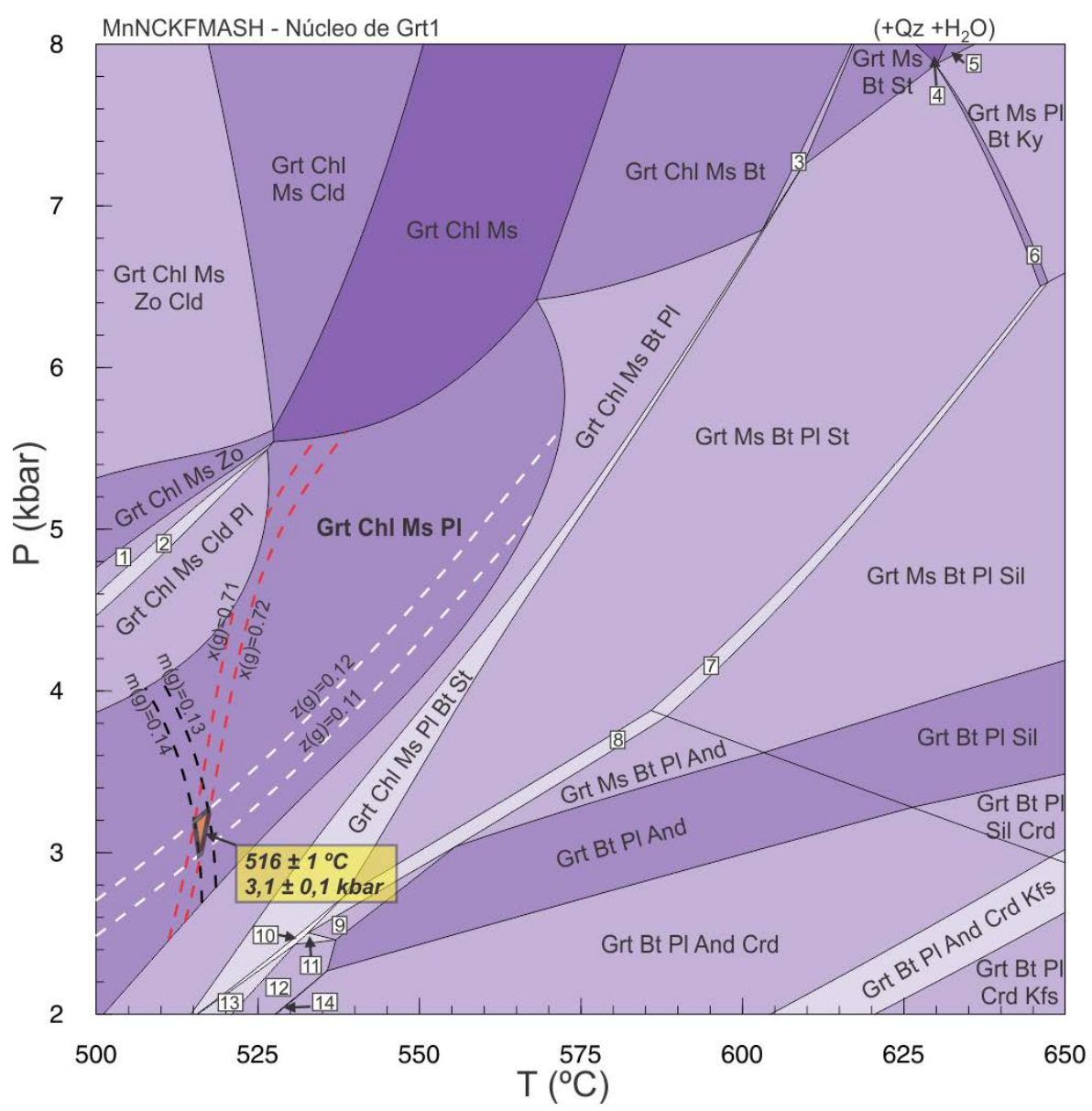

1 Grt Chl Ms Zo PI

2. Grt Chl Ms Zo PI Cld

3. Grt Chl Ms Bt St

4. Grt Ms Bt

5 Grt Ms Bt PI

6 Grt Ms Bt PI Ky

7 Grt Ms Bt PI St Sil

8 Grt Ms Bt PI St And

9 Grt Bt PI And St

10 Grt Chl Ms PI Bt St And

11. Grt Bt PI And St Chl

12. Grt Bt PI And Chl

13 Grt Bt PI And Chl Ms

14 Grt Bt PI And Chl Crd

FIG. 7. Pseudosección $P-T$ para el núcleo de Grt. Las condiciones de equilibrio de $3,1 \pm 0,1$ kbar y $516 \pm 1^{\circ} \mathrm{C}$ (área sombreada en naranja) fueron establecidas a partir de las isopletas de granate. $\mathrm{x}(\mathrm{g})=\mathrm{xalm}=\mathrm{Fe} /(\mathrm{Fe}+\mathrm{Mg}+\mathrm{Ca}+\mathrm{Mn}) . \mathrm{z}(\mathrm{g})=\mathrm{xgrs}=\mathrm{Ca} /(\mathrm{Ca}+\mathrm{Fe}+\mathrm{Mg}+\mathrm{Mn})$. $\mathrm{m}(\mathrm{g})=\mathrm{xsps}=\mathrm{Mn} /(\mathrm{Mn}+\mathrm{Fe}+\mathrm{Mg}+\mathrm{Ca})$.

efectiva para conocer las condiciones bajo las que se formó el borde del Grt. Dicha modificación se realiza mediante la función readbulkinfo (rbi) de THERMOCALC que es un script que se utiliza para conocer la composición química global a partir de las modas minerales y sus composiciones en un punto $P$ - $T$ determinado. Se realiza un rbi en el punto obtenido en la primera pseudosección (ca. 3,1 kbar y $516^{\circ} \mathrm{C}$ ). De esta manera se conocen las modas minerales y sus composiciones para las condiciones de equilibrio del núcleo del Grt. El paso siguiente consiste en hacer cero la moda de granate en ese punto, y así se obtiene la composición química global sin el núcleo del Grt ${ }_{1}$ (nueva composición química efectiva; Tabla 1).
Los resultados del modelado se muestran en la figura 8. La configuración y posición de los campos de estabilidad son similares a los obtenidos en la pseudosección anterior (Fig. 7). La principal diferencia es la desaparición de granate en las condiciones de la parte inferior del diagrama.

En esta etapa del progrado metamórfico se produciría la blástesis de estaurolita y $\mathrm{Bt}_{1}$ junto al borde del $\mathrm{Grt}_{1}$ (crecimiento continuo). Para conocer las condiciones $P$ - $T$ se utilizaron las isopletas calculadas para la composición del borde del Grt 1 (punto 18, ver figura 5). Dichas isopletas se intersectan en el campo con la asociación $\mathrm{Grt}+\mathrm{St}+\mathrm{Bt}+\mathrm{Ms}+\mathrm{Pl}+\mathrm{Qz}+\mathrm{H}_{2} \mathrm{O}$ limitando las condiciones de equilibrio a $5,4 \pm 1 \mathrm{kbar}$ y $576 \pm 17^{\circ} \mathrm{C}$ (área naranja de la figura 8). Las 


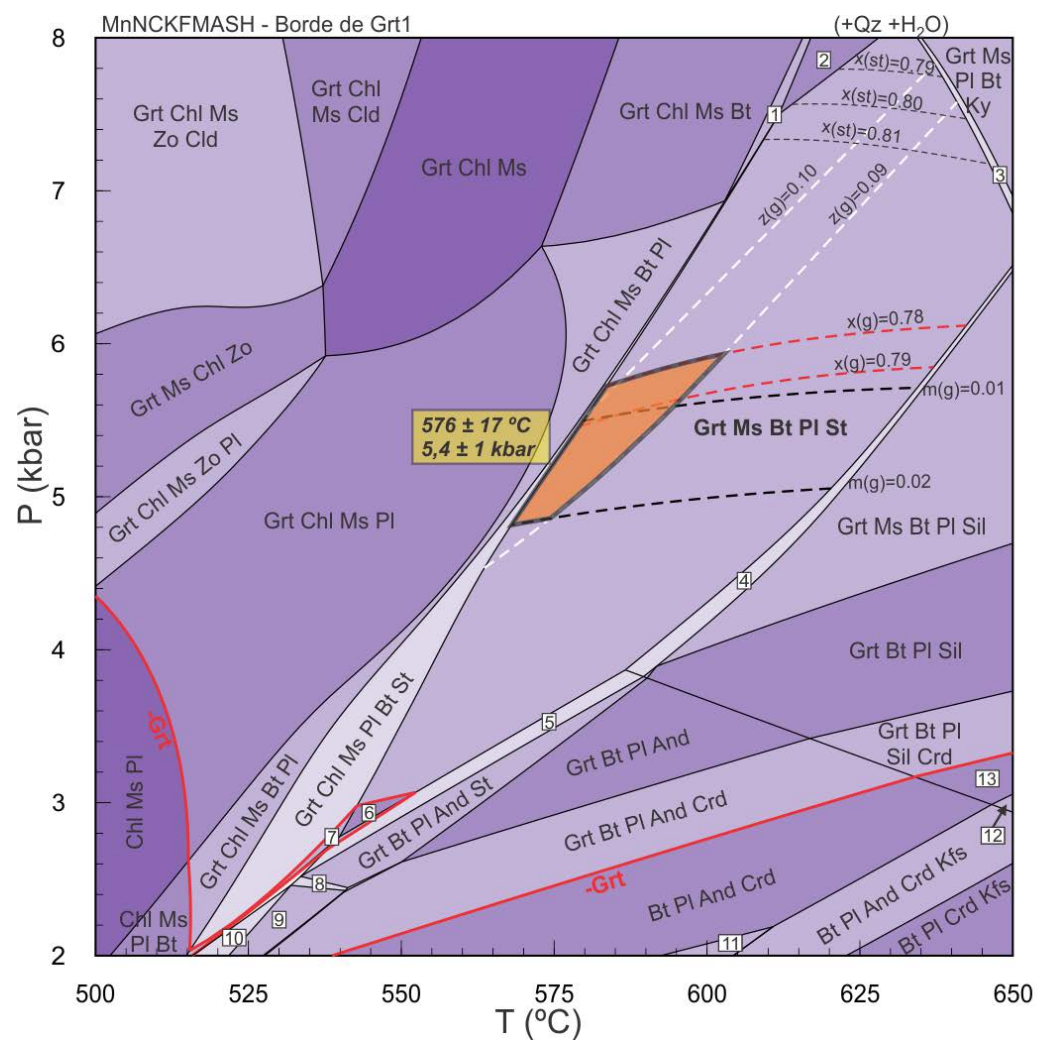

1 Grt Chl Ms Bt St

2) Grt Ms BtSt

3 Grt St Bt Ms PI Ky

4) Grt St Bt Ms PI Sil

5) Grt St Bt Ms PI And

6 $\mathrm{St} \mathrm{Bt} \mathrm{Ms} \mathrm{PI}$

$7 \mathrm{Chl}$ Ms PIBt St

8. St Bt PI And Grt Chl

9 Chl PI Bt And Grt

10Chl Ms PI Bt And Grt

11Bt PI And Crd Ms

12Bt PI Sil Crd Kfs

13. Bt PI Sil Crd

FIG. 8. Pseudosección $P-T$ para el borde de Grt. La línea continua roja marca la desaparición de granate hacia las zonas bajas del diagrama. Las condiciones de equilibrio de $5,4 \pm 1 \mathrm{kbar}$ y $576 \pm 17^{\circ} \mathrm{C}$ (área sombreada en naranja) fueron establecidas a partir de las isopletas de granate. $\mathrm{x}(\mathrm{g})=\mathrm{xalm}=\mathrm{Fe} /(\mathrm{Fe}+\mathrm{Mg}+\mathrm{Ca}+\mathrm{Mn}) \cdot \mathrm{z}(\mathrm{g})=\mathrm{xgrs}=\mathrm{Ca} /(\mathrm{Ca}+\mathrm{Fe}+\mathrm{Mg}+\mathrm{Mn}) \cdot \mathrm{m}(\mathrm{g})=\mathrm{xsps}=\mathrm{Mn} /(\mathrm{Mn}+\mathrm{Fe}+\mathrm{Mg}+\mathrm{Ca})$. $\mathrm{x}(\mathrm{st})=\mathrm{Fe} /(\mathrm{Fe}+\mathrm{Mg})$.

relaciones de $\mathrm{X}_{\mathrm{Fe}}$ ca. 0,80 de la estaurolita se encuentran a presiones mayores a las obtenidas con el granate (Fig. 8) lo que podría estar indicando un proceso de difusión sufrido probablemente durante la blástesis de $\mathrm{Grt}_{2}$.

\subsection{Pseudosección $P-T$ para $\mathrm{Grt}_{2}$}

Esta pseudosección se elaboró en el sistema NCKFMASH $\left(\mathrm{Na}_{2} \mathrm{O}-\mathrm{CaO}-\mathrm{K}_{2} \mathrm{O}-\mathrm{FeO}-\mathrm{MgO}-\mathrm{Al}_{2} \mathrm{O}_{3}\right.$ $\mathrm{Si}_{2} \mathrm{O}-\mathrm{H}_{2} \mathrm{O}$ ). El Mn fue quitado del sistema debido a que el $\mathrm{Grt}_{2}$ posee contenidos muy bajos de dicho elemento ( $\mathrm{Sps}=0,01)$. La información textural sugiere que tanto el Grt 1 como la estaurolita no habrían participado en forma significativa (en volumen) en las reacciones que dieron lugar a la formación de Grt, y por lo tanto se sustrajo de la composición global la moda de ambos minerales para calcular las condiciones de equilibrio durante esta etapa. Para realizar esta operación se utilizó la metodología descrita en la pseudosección anterior.

La pseudosección obtenida se muestra en la figura 9. La biotita, plagioclasa y el cuarzo son estables en todo el rango $P-T$. El granate es estable a partir de los $c a .7$ kbar (línea continua roja). La clorita se encuentra a temperaturas menores a $575^{\circ} \mathrm{C}$, en tanto que la muscovita desaparece en las condiciones del borde inferior derecho del diagrama, a expensas de la blástesis de feldespato potásico. En las mismas condiciones se encuentra la cordierita. La zoisita es estable en las condiciones del borde superior izquierdo del diagrama, lugar en el cual las asociaciones se encuentran $\sin \mathrm{H}_{2} \mathrm{O}$.

Para estimar las condiciones de equilibrio de esta etapa se utilizan las isopletas calculadas para la composición de $\mathrm{Grt}_{2}$, las cuales se intersectan en el campo con $\mathrm{Grt}+\mathrm{Bt}+\mathrm{Ms}+\mathrm{Pl}+\mathrm{Qz}+\mathrm{H}_{2} \mathrm{O}$ y arrojan valores de $9,2 \pm 0,5$ kbar y $642 \pm 17^{\circ} \mathrm{C}$. 


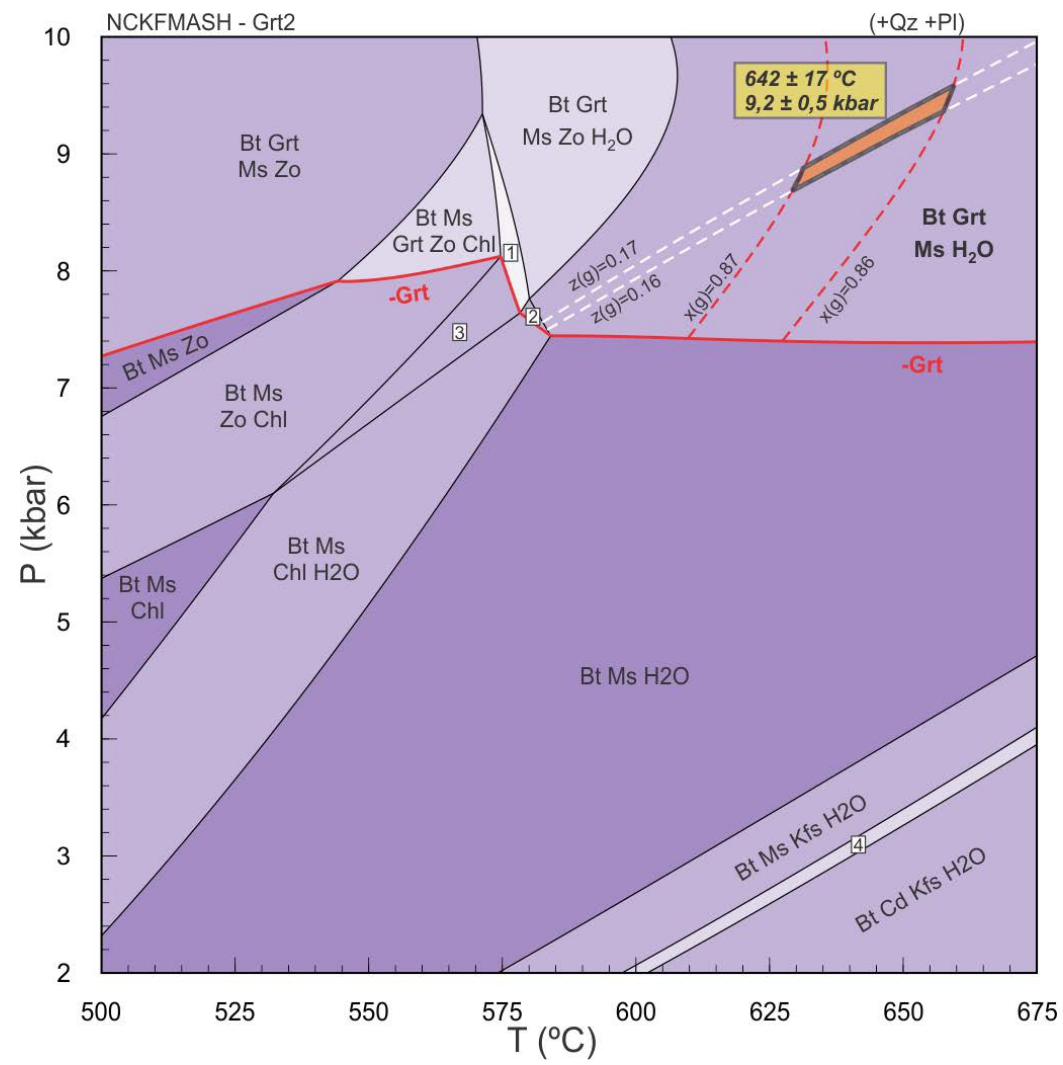

(1) Bt Ms Grt Zo Chl H2O

2. Bt Ms Chl Grt H2O

[3) $\mathrm{Bt} \mathrm{Ms} \mathrm{Chl} \mathrm{Zo} \mathrm{H2O}$

4. $\mathrm{Bt} \mathrm{Ms} \mathrm{Kfs} \mathrm{Cd} \mathrm{H2O}$

FIG. 9. Pseudosección $P-T$ para el Grt. La línea continua roja marca la desaparición de granate hacia las zonas bajas del diagrama. Las condiciones de equilibrio de $9,2 \pm 0,5 \mathrm{kbar}$ y $642 \pm 17^{\circ} \mathrm{C}$ (área sombreada en naranja) fueron establecidas a partir de las isopletas de granate. $\mathrm{x}(\mathrm{g})=\mathrm{Fe} /(\mathrm{Fe}+\mathrm{Mg}) \cdot \mathrm{z}(\mathrm{g})=\mathrm{Ca} /(\mathrm{Ca}+\mathrm{Fe}+\mathrm{Mg})$.

\section{Discusión}

\subsection{Trayectoria $P-T$}

Los trabajos sobre metamorfismo realizados en la SPP indican que hay dos eventos metamórficos: uno mesoproterozoico (grenvilliano) y otro ordovícico (famatiniano) (Dalla Salda 1984, Baldo et al., 1998; Casquet et al., 2001; Mulcahy et al., 2007, 2011; van Staal et al., 2011; Garber et al., 2014), lo que indicaría que las secuencias neoproterozoicascámbricas, donde se encuentra la muestra analizada SPP-27002, corresponden a unidades afectadas solo por el metamorfismo ordovícico famatiniano. La figura 10 es un diagrama en el que se han representado los tres puntos o áreas $P-T$ calculados para el esquisto estaurolítico, como así también se ha trazado la trayectoria seguida por la roca. El primer tramo de la trayectoria corresponde al período entre la blástesis del núcleo y el borde del Grt durante el cual la roca pasa de $c a .3$ kbar y $515^{\circ} \mathrm{C}$ a ca. 5,5 kbar y $575{ }^{\circ} \mathrm{C}$, marcando un alto gradiente $P / T$ (e.g., Brown et al., 2014). Luego de alcanzar los ca. 5,5 kbar la roca sufriría una leve disminución en la temperatura marcada localmente por un consumo de Grt y retrogradación de estaurolita a muscovita. A continuación se produciría la blástesis de $\mathrm{Grt}_{2}$ junto con muscovita orientada y $\mathrm{Bt}_{2}$ definiendo la $\mathrm{S}_{1}$ en condiciones de $c a .9$ kbar y $640^{\circ} \mathrm{C}$ continuando con un alto gradiente $P / T$. La muestra estudiada no proporciona información sobre la historia retrógrada. Baldo et al. (1998) y Casquet et al. (2001) determinan, en una muestra situada estructuralmente por debajo de la roca aquí estudiada, una trayectoria de sentido horario. También van Staal et al. (2011) interpretan sus resultados $P-T$ obtenidos en la parte estructural 


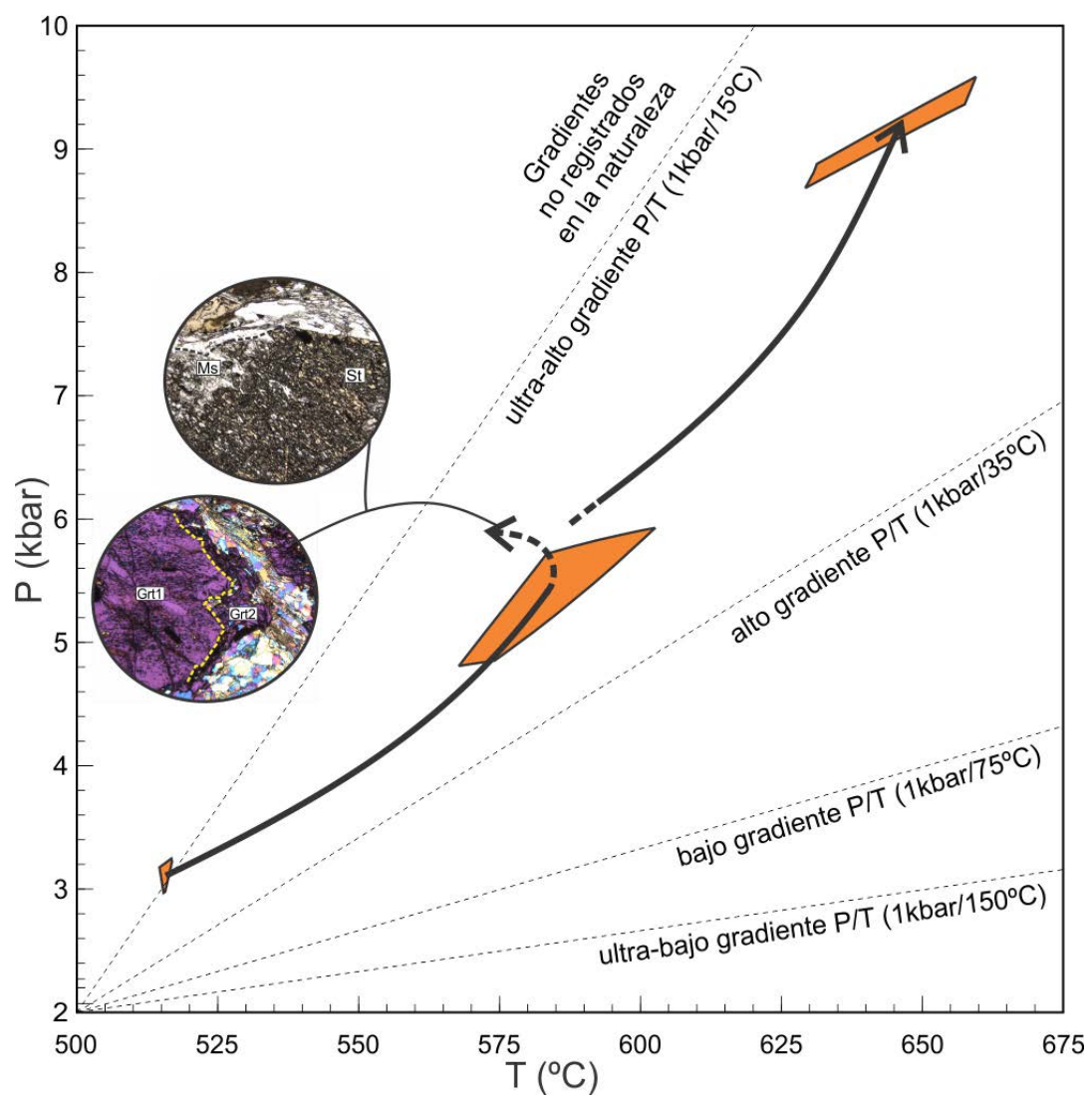

FIG. 10. Diagrama $P-T$ mostrando las tres áreas de equilibrio obtenidas en las tres pseudosecciones y la trayectoria seguida por la roca. Se muestran las pendientes de los diferentes gradientes $P / T$ tomado de Brown et al. (2014).

más baja de SPP (Grupo Caucete y Complejo de Pie de Palo) como una trayectoria horaria, lo que implica una descompresión seguida por enfriamiento.

\subsection{Implicancias geodinámicas en el antearco famatiniano}

Como se mencionó en la sección de introducción, el bloque de Pie de Palo fue interpretado originalmente como el basamento de la plataforma carbonática de la Precordillera, formando parte del terreno compuesto Cuyania, y que por lo tanto habría formado parte de la placa inferior durante la subducción y posterior colisión de dicho terreno al margen suroccidental de Gondwana en el Ordovícico (e.g., Astini et al., 1995; Ramos, 2004). Esta idea surgió tras el hallazgo de xenolitos en rocas volcánicas miocenas en la Precordillera, los cuales fueron datados como grenvillianos (Abbruzzi et al., 1993). Estas rocas mesoproterozoicas, no expuestas en la Precordillera, fueron correlacionadas con el basamento aflorante en la SPP. Esta correlación, basada en la edad de las rocas, sumada a la existencia de un lineamiento de primer orden hacia el este de la SPP (Lineamiento Bermejo o Valle Fértil; Fig. 1) fueron las evidencias más fuertes que llevaron a postular que el bloque de Pie de Palo y la Precordillera formarían parte de un único terreno (Ramos et al., 1998) y que dicho lineamiento correspondería a una zona de sutura continental. Sin embargo, trabajos posteriores han mostrado la existencia de rocas mesoproterozoicas hacia el este del lineamiento de Valle Fértil (complejo Resina; McClelland et al., 2005), lo que invalida el criterio de la edad de las rocas para separar estos bloques continentales a ambos lados de dicho lineamiento. Además, no se han encontrado complejos ofiolíticos, ni ninguna otra evidencia geológica que sugieran el cierre de un océano a lo largo de esta estructura. 
Los estudios realizados en los últimos años indican que el bloque de Pie de Palo se encontraría anexado a Gondwana desde el Cámbrico Inferior, y por lo tanto formaría parte de la placa superior durante la subducción famatiniana (e.g., Mulcahy et al., 2007, 2011; Ramacciotti et al., 2018). Las evidencias en las que se fundamenta esta interpretación son las siguientes: 1) edades $\left({ }^{40} \mathrm{Ar} /{ }^{39} \mathrm{Ar}\right)$ de $c a .515 \mathrm{Ma}$ en anfíboles de anfibolitas por encima del cabalgamiento Pirquitas, atribuidas por Mulcahy et al. (2007) al inicio de la subducción bajo el margen Gondwánico en el Cámbrico Inferior a Medio; 2) la existencia de rocas ígneas félsicas y máficas ordovícicas pertenecientes al magmatismo del antearco famatiniano (Pankhurst y Rapela, 1998; Baldo et al., 2012; Ramacciotti et al., 2014, 2017), y 3) es fundamental el reconocimiento de rocas metasedimentarias en la SPP cuyos protolitos habrían sido depositados durante el Cámbrico con una proveniencia gondwánica (Ramacciotti et al., 2018). Ello incluye el Grupo Caucete, por lo que tanto el supuesto basamento del mismo (el Complejo de Pie de Palo; van Staal et al., 2011) como el propio Grupo Caucete serían parte del margen de Gondwana y no parte del terreno Cuyania previo a la orogenia Famatiniana.

Las evidencias mostradas en los trabajos mencionados en el párrafo anterior son difíciles de explicar si el bloque de Pie de Palo se hubiese encontrado en la placa inferior durante la subducción Famatiniana, y consideramos que son suficientemente probatorias de que este bloque se encontraba formando parte de la placa superior durante dicha subducción. Es por esto que en este trabajo se analizan los datos de metamorfismo obtenidos en este trabajo y los previamente publicados en un contexto de placa superior aunque estos por sí solos no pueden discriminar entre las dos hipótesis mencionadas. Mulcahy et al. (2011) postulan que el bloque de Pie de Palo se ubicaría en la región de antearco durante la orogénesis famatiniana en base al evento deformacional de ca. $515 \mathrm{Ma}$ (Mulcahy et al., 2007). Igual ubicación tectónica ha sido propuesta para Loma de Las Chacras (Casquet et al., 2012b), un pequeño bloque de basamento orodvícico ubicado inmediatamente al este de la SPP y al oeste del lineamiento de Bermejo (Fig. 1). Casquet et al. (2012b) postulan que Loma de Las Chacras correspondería a una cuenca sedimentaria de antearco en la cual se habrían depositado sedimentos clásticos con circones de ca. 470 Ma procedentes del propio arco magmático famatiniano. Dichos sedimentos se habrían enterrado rápidamente bajo el arco (underplating) alcanzando presiones de $c a .12 \mathrm{kbar}$ y $780^{\circ} \mathrm{C}$ casi a la misma edad que el magmatismo. La presión de $c a .9 \mathrm{kbar}$ alcanzada por el esquisto SPP-27002 es compatible con el engrosamiento cortical propuesto por Casquet et al. (2012b) para el antearco famatiniano.

En la figura 11 se muestra un diagrama $P-T$ con las facies metamórficas en el cual se han proyectado todas las muestras de la SPP de las cuales se conocen las condiciones termobarométricas, además de las rocas de Loma de Las Chacras y la caja metamórfica del arco magmático famatiniano de la Sierra de Valle Fértil-La Huerta (Fig. 1). Las rocas de la SPP, se han subdividido en varias unidades separadas por contactos tectónicos basadas en los trabajos de Casquet et al. (2001), Mulcahy et al. (2011) y Ramacciotti (2016). La mayoría de ellas corresponden a condiciones $P-T$ en facies de esquistos verdes y anfibolitas, dos cercanas a las facies de eclogitas, y tres en facies de esquistos azules, a pesar de que no se han encontrado aún esquistos azules ni eclogitas en SPP probablemente debido a causas composicionales (van Staal et al., 2011). Las rocas de Loma de Las Chacras alcanzan las facies de granulitas, con presiones similares a las de la SPP, pero con temperaturas que llegan a los ca. $900^{\circ} \mathrm{C}$. Por otra parte, la caja del arco magmático de Valle Fértil-La Huerta se encuentra mayormente en facies de granulitas, pero con presiones menores (mayoritariamente entre 6-8 kbar) a las encontradas en el antearco (mayoritariamente entre 8 y 14 kbar).

La figura 12 muestra la variación E-O de las condiciones $P-T$ en el antearco famatiniano desde Loma de Las Chacras al este, hasta el Grupo Caucete en la SPP al oeste, encontrándose una disminución en las condiciones termobarométricas en dicho sentido. La muestra analizada (SPP-27002; Unidad El Indio) posee una presión inferior a la esperada según la línea de tendencia mostrada en la figura 12. Dicha diferencia puede deberse a causas geológicas (e.g., diferentes grados de enterramiento de las láminas de corrimiento) o a cuestiones metodológicas, ya que las muestras analizadas en trabajos previos han sido tratadas con termobarómetros convencionales. En cualquier caso los 9 kbar obtenidos en este trabajo son compatibles con el engrosamiento del antearco propuesto por Casquet et al. (2012b).

Las edades del metamorfismo famatiniano, de los infracorrimientos y del propio arco magmático son muy coincidentes dentro de los límites de 


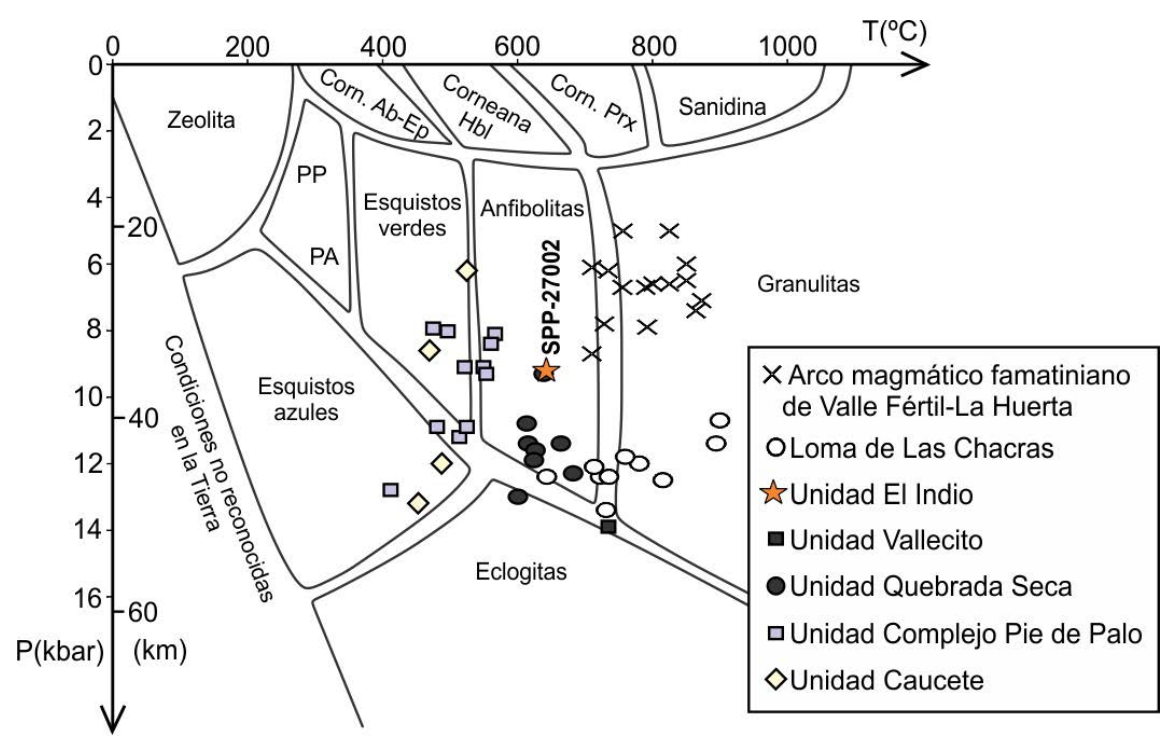

FIG. 11. Diagrama P-T mostrando las facies metamórficas en el antearco (Sierra de Pie de Palo y Loma de Las Chacras) y arco magmático famatiniano (Sierra de Valle Fértil-La Huerta). Los datos termobarométricos fueron tomados de Casquet et al. (2001, 2012a), Galindo et al. (2004), Murra y Baldo (2006), Mulcahy et al. (2007, 2011), Delpino et al. (2008), Otamendi et al. (2008), Gallien et al. (2010), Tibaldi et al. (2011, 2013), van Staal et al. (2011), Gallien et al. (2012), Garber et al. (2014), Mulcahy et al. (2014). Los límites de facies se basan en la figura 3.4 de Nicollet (2013). Los colores de las unidades son coincidentes con los mostrados en el mapa de la figura 2.

error entre ca. 465 y 470 Ma (e.g., Ramos et al., 1998; Casquet et al., 2001, 2012b; Ducea et al., 2017). Interpretamos que el extenso basamento que constituyó el antearco famatiniano fue acortado y engrosado mediante grandes infracorrimientos con vergencia al oeste, muy cercano en el tiempo con el desarrollo del magmatismo en el arco. Este antearco se convirtió así en una cuña imbricada de basamento prefamatiniano, con sedimentos sinorogénicos solo reconocidos hasta el momento en Loma de Las Chacras (Casquet et al., 2012b). Las diferencias de temperaturas registradas de este a oeste desde $c a .900^{\circ} \mathrm{C}$ en Loma de Las Chacras, a ca. $450{ }^{\circ} \mathrm{C}$ en torno del cabalgamiento Pirquitas, indican un descenso progresivo del gradiente geotérmico hacia el oeste dentro de la cuña imbricada, desde $c a .85^{\circ} \mathrm{C} / \mathrm{kbar}$ junto al arco a $c a .35^{\circ} \mathrm{C} / \mathrm{kbar}$ en la parte más alejada del mismo. Los procesos de engrosamiento cortical debido al infracorrimiento (underthrusting) de antearcos bajo arcos magmáticos han sido reconocido en otros orógenos colisionales, como por ejemplo en los gneises de Swakane en la cordillera de las Cascadas en Norteamérica, cuyos protolitos fueron depositados en un antearco en el Cretácico tardío y enterrados a profundidades equivalentes a 9-12 kbar de presión en ca. $5 \mathrm{Ma}$ (Matzel y Bowring, 2004). Otros ejemplos de estos procesos pueden encontrarse en el orógeno de Taiwan (Malavieille y Trullenque, 2009), en el terreno de Monterrey, California (Ducea et al., 2009), o en el orógeno colisional del arco de Banda-NO Australia (Standley y Harris, 2009).

El significado geotectónico del acortamiento y engrosamiento del antearco famatiniano es, por el momento, incierto. Todavía no se ha reconocido la ubicación del límite del margen continental al oeste del antearco en el Ordovícico Inferior a Medio, ni una sutura de dicha edad. En cualquier caso, esta fase de acortamiento se puede comparar con el tipo de orógeno acreccionario en avance (Advancing Accretionary Orogen de Cawood et al., 2009) y ser imputable a cualquiera de las siguientes causas: 1) subducción de litosfera oceánica boyante; 2) acrección de terrenos; 3) reorganización de placas y aumento de la velocidad de convergencia (Cawood et al., 2009).

\section{Conclusiones}

En la Sierra de Pie de Palo se encuentran registrados dos eventos tectonotermales: el primero, de edad mesoproterozoica, corresponde a la orogénesis 


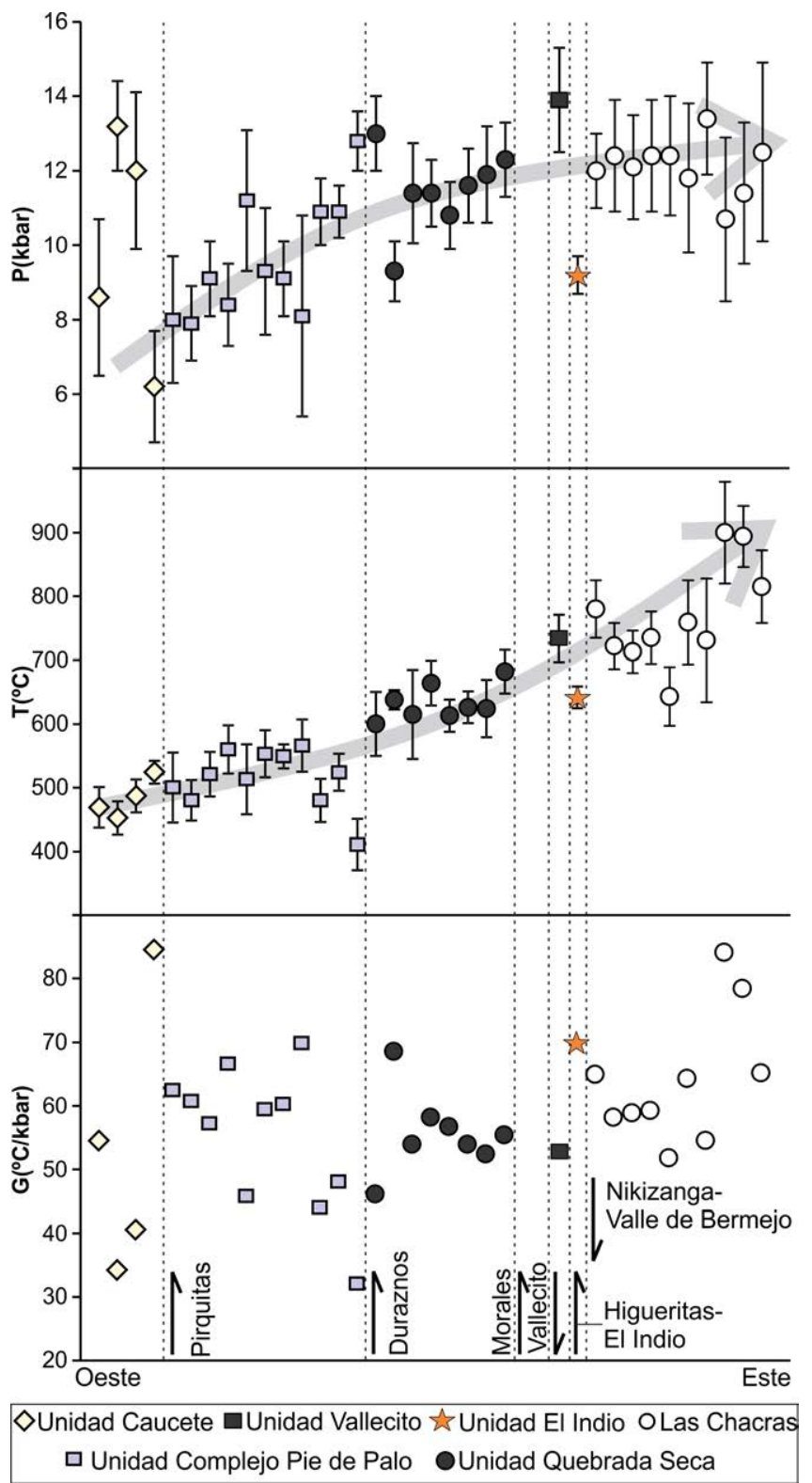

FIG. 12. Variación de presión (P), temperatura (T) y gradiente geotérmico $(\mathrm{G})$ a través del antearco famatiniano de oeste a este. La base de datos es la misma que en la figura 11. Las estructuras marcadas corresponden a las zonas de cizalla dúctil de la Sierra de Pie de Palo. Los colores de las unidades son coincidentes con los mostrados en el mapa de la figura 2.

Grenvilliana ( $c a .1,0-1,1 \mathrm{Ga})$ mientras que el segundo, de edad ordovícica, se encuentra registrado en las cubiertas sedimentarias neoproterozoicas a cámbricas (SMDC y grupos Caucete y Nikizanga) y es atribuido a la orogénesis Famatiniana. El modelado de equilibrio de fases minerales realizado en este trabajo indica que las rocas del sector sureste de la sierra sufrieron un metamorfismo en facies de anfibolitas pasando progresivamente de $c a .3 \mathrm{kbar}$ y $515^{\circ} \mathrm{Ca} c a .9 \mathrm{kbar}$ y $640{ }^{\circ} \mathrm{C}$, marcando un gradiente $P / T$ alto para el metamorfismo famatiniano en este sector de las Sierras Pampeanas. 
El antearco famatiniano, del cual forman parte las rocas de Loma de Las Chacras y la Sierra de Pie de Palo, muestra una disminución en las condiciones $P-T$ y el gradiente geotérmico desde las adyacencias al arco magmático donde las rocas se encuentran en facies de granulitas (Loma de Las Chacras, ca. $85^{\circ} \mathrm{C} / \mathrm{kbar}$ ), hacia el margen continental activo al oeste, donde las rocas se encuentran predominantemente en facies de esquistos verdes y anfibolitas (SPP, ca. $35^{\circ} \mathrm{C} / \mathrm{kbar}$ ). Este antearco fue acortado y engrosado mediante infracorrimientos dirigidos hacia el oeste al mismo tiempo que ocurría el magmatismo de arco en la Sierra de Valle FértilLa Huerta, convirtiéndose así en parte de la cuña acrecionaria frontal de la orogenia Famatiniana.

\section{Agradecimientos}

Este trabajo fue financiado con los siguientes proyectos Argentinos: PUE 2016 CONICET-CICTERRA, CONICET PIP 2015-2018 11220150100901CO, FONCYT PICT 0472, SECyT 2016-2017 Tipo A N 30720150100517CB, y Españoles CGL2016-76439-P de MINECO. Este artículo es parte de la tesis doctoral del Dr. C.D. Ramacciotti. Agradecemos a todos los miembros del grupo PAMPRE, en especial al Dr. F. Colombo por la asistencia en el microanálisis de minerales. Agradecemos al Dr. J. Otamendi y a un revisor anónimo por los comentarios y sugerencias realizadas, las cuales contribuyeron a una mejora de este artículo, y al editor W. Vivallo por el trabajo editorial.

\section{Referencias}

Abbruzzi, J.; Kay, S.M.; Bickford, M.E. 1993. Implications for the nature of the Precordilleran basement from Precambrian xenoliths in miocen volcanic rocks, San Juan province, Argentina. In Congreso Geológico Argentino, No. 12, y Congreso de Exploración de Hidrocarburos, No. 2, Actas: 3 331-338, Mendoza.

Aceñolaza, G.F.; Toselli, A.J. 1973. Consideraciones estratigráficas y tectónicas sobre el Paleozoico Inferior del Noroeste Argentino. In Congreso Latinoamericano de Geología, No 2: 755-764. Caracas.

Alasino, P.H.; Casquet, C.; Larrovere, M.A.; Pankhurst, R.J.; Galindo, C.; Dahlquist, J.A.; Baldo, E.G.; Rapela, C.W. 2014. The evolution of a mid-crustal thermal aureole at Cerro Toro, Sierra de Famatina, NW Argentina. Lithos 190-191: 154-172.

Astini, R.A.; Dávila, F.M. 2004. Ordovician back arc foreland and Ocloyic thrust belt development on the western Gondwana margin as a response to Precordillera terrane accretion. Tectonics 23: 1-19.

Astini, R.A.; Benedetto, J.L.; Vaccari, N.E. 1995. The early Paleozoic evolution of the Argentine Precordillera as a Laurentian rifted, drifted, and collided terrane: a geodynamic model. Geological Society of America Bulletin 107: 253-273.

Baldo, E.G.; Casquet, C.; Galindo, C. 1998. Datos preliminares sobre el metamorfismo de la Sierra de Pie de Palo. Geogaceta 24: 39-43.

Baldo, E.G.; Casquet, C.; Pankhurst, R.J.; Galindo, C.; Rapela, C.W.; Fanning, C.M.; Dahlquist, J.A.; Murra, J. 2006. Neoproterozoic A-type magmatism in the Western Sierras Pampeanas (Argentina): Evidence for Rodinia break-up along a proto-lapetus rift? Terra Nova 18: 388-394.

Baldo, E.G.; Dahlquist, J.A.; Casquet, C.; Rapela, C.W.; Pankhurst, R.J.; Galindo, C.; Fanning, C.M. 2012. Ordovician peraluminous granites in the Sierra de Pie de Palo, Western Sierras Pampeanas of Argentina: Geotectonic Implications. Geotemas 13: 1907-1910.

Brown, M. 2014. The contribution of metamorphic petrology to understanding lithosphere evolution and geodynamics. Geoscience Frontiers 5: 553-569.

Büttner, S.H.; Glodny, J.; Lucassen, F.; Wemmer, K.; Erdmann, S.; Handler, R.; Franz, G. 2005. Ordovician metamorphism and plutonism in the Sierra de Quilmes metamorphic complex: Implications for the tectonic setting of the northern Sierras Pampeanas (NW Argentina). Lithos 83: 143-181.

Casquet, C.; Baldo, E.G.; Pankhurst, R.J.; Rapela, C.W.; Galindo, C.; Fanning, C.M.; Saavedra, J. 2001. Involvement of the Argentine Precordillera terrane in the Famatinian mobile belt: U-Pb SHRIMP and metamorphic evidence from the Sierra de Pie de Palo. Geology 29: 703-706.

Casquet, C.; Rapela, C.W.; Pankhurst, R.J.; Baldo, E.G.; Galindo, C.; Fanning, C.M.; Dahlquist, J.A. 2012a. Fast sediment underplating and essentially coeval juvenile magmatism in the Ordovician margin of Gondwana, Western Sierras Pampeanas, Argentina. Gondwana Research 22: 664-673.

Casquet, C.; Rapela, C.W.; Pankhurst, R.J.; Baldo, E.G.; Galindo, C.; Fanning, C.M.; Dahlquist, J.A.; Saavedra, J. 2012b. A history of Proterozoic terranes in southern South America: From Rodinia to Gondwana. Geoscience Frontiers 3: 137-145.

Casquet, C.; Dahlquist, J.A.; Verdecchia, S.O.; Baldo, E.G.; Galindo, C.; Rapela, C.W.; Pankhurst, R.J.; Morales, M.M.; Murra, J.A.; Fanning, C.M. 2018. Review of the 
Cambrian Pampean orogeny of Argentina; a displaced orogen formerly attached to the Saldania Belt of South Africa? Earth-Science Reviews 177: 209-225.

Castro de Machuca, B.; Arancibia, G.; Morata, D.; Belmar, M.; Previley, L.; Pontoriero, S. 2008. P-T-t evolution of an Early Silurian medium-grade shear zone on the west side of the Famatinian magmatic arc, Argentina: Implications for the assembly of the Western Gondwana margin. Gondwana Research 13: 216-226.

Cawood, P.A.; Kroner, A.; Collins, W.J.; Kusky, T.M.; Mooney, W.D.; Windley, B.F. 2009. Accretionary orogens through Earth history. Geological Society, London, Special Publications 318: 1-36.

Coggon, R.; Holland, T.J.B. 2002. Mixing properties of phengitic micas and revised garnet-phengite thermobarometers. Journal of Metamorphic Geology 20: 683-696.

Dahlquist, J.A.; Baldo, E.G. 1996. Metamorfismo y deformación famatinianos en la Sierra de Chepes. In Congreso Geológico Argentino, No. 13 y Congreso Geológico de Hidrocarburos, No. 3: 393-409. Buenos Aires.

Dahlquist, J.A.; Rapela, C.W.; Baldo, E.G. 2005. Petrogenesis of cordierite-bearing S-type granitoids in Sierra de Chepes, Famatinian orogen, Argentina. Journal of South American Earth Sciences 20: 231-251.

Dahlquist, J.A.; Pankhurst, R.J.; Rapela, C.W.; Galindo, C.; Alasino, P.H.; Fanning, C.M.; Saavedra, J.; Baldo, E.G. 2008. New SHRIMP U-Pb data from the Famatina Complex: Constraining Early-Mid Ordovician Famatinian magmatism in the Sierras Pampeanas, Argentina. Geologica Acta 6: 319-333.

Dahlquist, J.A.; Rapela, C.W.; Pankhurst, R.J.; Fanning, C.M.; Vervoort, J.D.; Hart, G.; Baldo, E.G.; Murra, J.A.; Alasino, P.H.; Colombo, F. 2012. Age and magmatic evolution of the Famatinian granitic rocks of Sierra de Ancasti, Sierras Pampeanas, NW Argentina. Journal of South American Earth Sciences 34: 10-25.

Dalla Salda, L.; Varela, R. 1984. El metamorfismo en el tercio sur de la Sierra de Pie de Palo, San Juan. Revista de la Asociacion Geologica Argentina 39: 68-93.

Delpino, S.H.; Bjerg, E.A.; Ferracutti, G.R.; Mogessie, A. 2007. Counterclockwise tectonometamorphic evolution of the Pringles Metamorphic Complex, Sierras Pampeanas of San Luis (Argentina). Journal of South American Earth Sciences 23: 147-175.

Delpino, S.; Bjerg, E.; Mogessie, A.; Schneider, I.; Gallien, F.; Castro de Machuca, B.; Previley, L.; Meissl, E.; Pontoriero, S.; Kostadinoff, J. 2008. Mineral deformation mechanisms in granulite facies, Sierra de Valle Fértil, San Juan province: Evelopment conditions constrained by the P-T metamorphic path. Revista de la Asociacion Geologica Argentina 63: 181-195.

Ducea, M.N.; Kidder, S.; Chesley, J.T.; Saleeby, J.B. 2009. Tectonic underplating of trench sediments beneath magmatic arcs: The central California example. International Geology Review 51: 1-26.

Ducea, M.N.; Otamendi, J.E.; Bergantz, G.W.; Stair, K.M.; Valencia, V.A.; Gehrels, G.E. 2010. Timing constraints on building an intermediate plutonic arc crustal section: $\mathrm{U}-\mathrm{Pb}$ zircon geochronology of the Sierra Valle Fértil-La Huerta, Famatinian arc, Argentina. Tectonics 29. TC4002.

Ducea, M.N.; Bergantz, G.W.; Crowley, J.L.; Otamendi, J.E. 2017. Ultrafast magmatic buildup and diversification to produce continental crust during subduction. Geology: G38726.1.

Finney, S.C. 2007. The parautochthonous Gondwanan origin of the Cuyania (greater Precordillera) terrane of Argentina: A re-evaluation of evidence used to support an allochthonous Laurentian origin. Geologica Acta 5: 127-158.

Galindo, C.; Casquet, C.; Rapela, C.W.; Pankhurst, R.J.; Baldo, E.G.; Saavedra, J. 2004. Sr, C and O isotope geochemistry and stratigraphy of Precambrian and lower Paleozoic carbonate sequences from the Western Sierras Pampeanas of Argentina: Tectonic implications. Precambrian Research 131: 55-71.

Gallien, F.; Mogessie, A.; Bjerg, E.; Delpino, S.; Castro de Machuca, B.; Thöni, M.; Klötzli, U. 2010. Timing and rate of granulite facies metamorphism and cooling from multi-mineral chronology on migmatitic gneisses, Sierras de La Huerta and Valle Fértil, NW Argentina. Lithos 114: 229-252.

Gallien, F.; Mogessie, A.; Hauzenberger, C.A.; Bjerg, E.; Delpino, S.; Castro de Machuca, B. 2012. On the origin of multi-layer coronas between olivine and plagioclase at the gabbro-granulite transition, Valle Fértil-La Huerta Ranges, San Juan Province, Argentina. Journal of Metamorphic Geology 30: 281-302.

Garber, J.M.; Roeske, S.M.; Warren, J.; Mulcahy, S.R.; McClelland, W.C.; Austin, L.J.; Renne, P.R.; Vujovich, G.I. 2014. Crustal shortening, exhumation, and strain localization in a collisional orogen: The Bajo Pequeño Shear Zone, Sierra de Pie de Palo, Argentina. Tectonics 33: 1277-1303.

Hauzenberger, C.A.; Mogessie, A.; Hoinkes, G.; Felfernig, A.; Bjerg, E.A.; Kostadinoff, J.; Delpino, S.; Dimieri, L. 2001. Metamorphic evolution of the Sierras de San Luis, Argentina: Granulite facies metamorphism related to mafic intrusions. Mineralogy and Petrology 71: 95-126. 
Herron, M.M. 1988. Geochemical Classification of Terrigenous Sands and Shales from Core or Log Data. Journal of Sedimentary Petrology 58: 820-829.

Holland, T.J.B.; Powell, R. 1998. An internally consistent thermodynamic data set for phases of petrological interest. Journal of Metamorphic Geology 16: 309-343.

Holland, T.; Powell, R. 2003. Activity-compositions relations for phases in petrological calculations: An asymetric multicomponent formulation. Contributions to Mineralogy and Petrology 145: 492-501.

Holland, T.J.B.; Baker, J.M.; Powell, R. 1998. Mixing properties and activity-composition relationships of chlorite in the system MgO-FeO-Al2O3-SiO2-H2O. European Journal of Mineralogy 10: 395-406.

Jordan, T.E.; Allmendinger, R.W. 1986. The Sierras Pampeanas of Argentina: a modern analogue of Rocky Mountain foreland deformation. American Journal of Science 286: 737-764.

Larrovere, M.A.; de los Hoyos, C.R.; Toselli, A.J.; Rossi, J.N.; Basei, M.A.S.; Belmar, M.E. 2011. High T/P evolution and metamorphic ages of the migmatitic basement of northern Sierras Pampeanas, Argentina: Characterization of a mid-crustal segment of the Famatinian belt. Journal of South American Earth Sciences 31: 279-297.

Lucassen, F.; Becchio, R. 2003. Timing of high-grade metamorphism: Early Palaeozoic U-Pb formation ages of titanite indicate long-standing high-T conditions at the western margin of Gondwana (Argentina, 2629??S). Journal of Metamorphic Geology 21: 649-662.

Mahar, E.M.; Beker, J.M.; Powell, R.; Holland, T.J.B.; Howell, N. 1997. The effect of Mn on mineral stability in metapelites. Journal of Metamorphic Geology 15: 223-238.

Malavieille, J.; Trullenque, G. 2009. Consequences of continental subduction on forearc basin and accretionary wedge deformation in SE Taiwan: Insights from analogue modeling. Tectonophysics 466: 377-394.

Matzel, J.E.P.; Bowring, S.A.; Miller, R.B. 2004. Protolith age of the Swakane Gneiss, North Cascades, Washington: Evidence of rapid underthrusting of sediments beneath an arc. Tectonics 23: 1-18.

McDonough, M.R.; Ramos, V.A.; Isachsen, C.E.; Bowring, S.A.; Vujovich, G.I. 1993. Edades preliminares de circones del basamento de la Sierra de Pie de Palo, Sierras Pampeanas Occidentales de San Juan: sus implicancias para el supercontinente proterozoico de Rodinia. In Congreso Geológico Argentino, No. 12 y Congreso de Exploración de Hidrocarburos, No. 2: 340-342. Mendoza.
Morata, D.; Castro de Machuca, B.; Arancibia, G.; Pontoriero, S.; Fanning, C.M. 2010. Peraluminous Grenvillian TTG in the Sierra de Pie de Palo, Western Sierras Pampeanas, Argentina: Petrology, geochronology, geochemistry and petrogenetic implications. Precambrian Research 177: 308-322.

Mulcahy, S.R.; Roeske, S.M.; McClelland, W.C.; Nomade, S.; Renne, P.R. 2007. Cambrian initiation of the Las Pirquitas thrust of the western Sierras Pampeans, Argentina: Implications for the tectonic evolution of the proto-Andean margin of South America. Geology 35: 443-446.

Mulcahy, S.R.; Roeske, S.M.; McClelland, W.C.; Jourdan, F.; Iriondo, A.; Renne, P.R.; Vervoort, J.D.; Vujovich, G.I. 2011. Structural evolution of a composite middle to lower crustal section: The Sierra de Pie de Palo, northwest Argentina. Tectonics 30.

Mulcahy, S.R.; Roeske, S.M.; McClelland, W.C.; Ellis, J.R.; Jourdan, F.; Renne, P.R.; Vervoort, J.D.; Vujovich, G.I. 2014. Multiple migmatite events and cooling from granulite facies metamorphism within the Famatina arc margin of northwest Argentina. Tectonics 33: 1-25.

Murra, J.A.; Baldo, E.G. 2006. Evolución tectonotermal ordovícica del borde occidental del arco magmático Famatiniano: metamorfismo de las rocas máficas y ultramáficas de la Sierra de la Huerta-de Las Imanas (Sierras Pampeanas, Argentina). Revista Geológica de Chile 33 (2): 277-298.doi: 10.5027/andgeoV33n2-a04.

Naipauer, M.; Vujovich, G.I.; Cingolani, C.A.; McClelland, W.C. 2010. Detrital zircon analysis from the Neoproterozoic-Cambrian sedimentary cover (Cuyania terrane), Sierra de Pie de Palo, Argentina: Evidence of a rift and passive margin system? Journal of South American Earth Sciences 29: 306-326.

Nicollet, C. 2013. Métamorphisme et Geodynamique. Dunod, 288 p. París.

Otamendi, J.E.; Tibaldi, A.M.; Vujovich, G.I.; Viñao, G.A. 2008. Metamorphic evolution of migmatites from the deep Famatinian arc crust exposed in Sierras Valle Fértil-La Huerta, San Juan, Argentina. Journal of South American Earth Sciences 25: 313-335.

Otamendi, J.E.; Ducea, M.N.; Cristofolini, E.A.; Tibaldi, A.M.; Camilletti, G.C.; Bergantz, G.W. 2017. Journal of South American Earth Sciences U-Pb ages and $\mathrm{Hf}$ isotope compositions of zircons in plutonic rocks from the central Famatinian arc, Argentina. Journal of South American Earth Sciences 76: 412-426.

Pankhurst, R.J.; Rapela, C.W. 1998. The proto-Andean margin of Gondwana: an introduction. In The proto- 
Andean margin of Gondwana (Pankhurst, R.J.; Rapela, W.C.; editors), Geological Society, Special Publications 142: 1-9. London.

Pankhurst, R.J.; Rapela, C.W.; Saavedra, J.; Baldo, E.G.; Dahlquist, J.A.; Pascua, I.; Fanning, C.M. 1998. The Famatinian magmatic arc in the central Sierras Pampeanas: an Early-to-Middle Ordovician continental arc on the Gondwana margin. In The proto-Andean margin of Gondwana (Pankhurst, R.J.; Rapela, W.C.; editors), Geological Society, Special Publications 142: 343-367.

Pankhurst, R.J.; Rapela, C.W.; Fanning, C.M. 2000. Age and origin of coeval TTG, I- and S-type granites in the Famatinian belt of NW Argentina. Transactions of the Royal Society of Edinburgh: Earth Sciences 91: 151-168.

Powell, R.; Holland, T.J.B. 1988. An internally consistent dataset with uncertainties and correlations: 3 . Applications to geobarometry, worked examples and a computer program. Journal of Metamorphic Geology 6: 173-204.

Powell, R.; Holland, T. 1999. Relating formulations of the thermodynamics of mineral solid solutions: Activity modeling of pyroxenes, amphiboles, and micas. American Mineralogist 84: 1-14.

Powell, R.; Holland, T.J.B. 2008. On thermobarometry. Journal of Metamorphic Geology 26: 155-179.

Ramacciotti, C.D. 2016. Petrología, geoquímica y geocronología del sector sureste de la Sierra de Pie de Palo, San Juan, Argentina (Unpublished) Ph.D. Thesis, Universidad Nacional de Córdoba: 204 p.

Ramacciotti, C.D.; Baldo, E.G.; Casquet, C. 2014. E1 magmatismo máfico en el sector sureste de la Sierra de Pie de Palo, San Juan, Argentina: implicancias geotectónicas. In Congreso Geológico Argentino, No. 19: S21-49. Córdoba.

Ramacciotti, C.D.; Baldo, E.G.; Casquet, C. 2015a. U-Pb SHRIMP detrital zircon ages from the Neoproterozoic Difunta Correa Metasedimentary Sequence (Western Sierras Pampeanas, Argentina): Provenance and paleogeographic implications. Precambrian Research 270: 39-49.

Ramacciotti, C.D.; Casquet, C.; Baldo, E.G.; Galindo, C. 2015b. The Difunta Correa metasedimentary sequence (NW Argentina): Relict of a Neoproterozoic platform? - Elemental and Sr-Nd isotope evidence. Revista Mexicana de Ciencias Geologicas 32: 395-414.

Ramacciotti, C.D.; Casquet, C.; Baldo, E.G. 2017. Edades $\mathrm{U}-\mathrm{Pb}$ SHRIMP en circones de granitos peraluminosos de la Sierra de Pie de Palo, Sierras Pampeanas Occidentales,
Argentina. In Congreso Geológico Argentino, No. 20: 99-100. Tucumán.

Ramacciotti, C.D.; Casquet, C.; Baldo, E.G.; Galindo, C.; Pankhurst, R.J.; Verdecchia, S.O.; Rapela, C.W.; Fanning, C.M. 2018. A Cambrian mixed carbonatesiliciclastic platform in SW Gondwana: evidence from the Western Sierras Pampeanas (Argentina) and implications for the early Paleozoic paleogeography of the proto-Andean margin. International Journal of Earth Sciences 107: 2605-2625.

Ramos, V.A. 2004. Cuyania, an Exotic Block to Gondwana: Review of a Historical Success and the Present Problems. Gondwana Research 7: 1009-1026.

Ramos, V.A. 2018. The Famatinian orogen along the protomargin of Western Gondwana: Evidence for a nearly continuous Ordovician magmatic arc between Venezuela and Argentina. In The Evolution of the Chilean-Argentinian Andes (Folguera, A.;ContrerasReyes, E.; Heredia, N.;Encinas, A.; Iannelli, S.B; Oliveros, V.; Dávila, F.M.; Collo, G.; Giambiagi, L.; Maksymowicz, A.; Iglesia Llanos, M.P.; Turienzo, M.; Naipauer, N.; Orts, D.; Litvak, V.D.; Álvarez O.; Arriagada, C.; editors) Springer Earth System Sciences: 154-183.

Ramos, V.A.; Dallmeyer, R.D.; Vujovich, G.I. 1998. Time constraints on the Early Paleozoic docking of the Precordillera, central Argentina. In Geological Society, London (Pankhurst, R.J.; Rapela, C.W.; editors). Special Publications 142: 143-158.

Rapela, C.W.; Pankhurst, R.J.; Casquet, C.; Fanning, C.M.; Galindo, C.; Baldo, E.G. 2005. Datación U-Pb SHRIMP de circones detríticos en paranfibolitas neoproterozoicas de la secuencia Difunta Correa (Sierras Pampeanas Occidentales, Argentina). Geogaceta 38: 227-230.

Rapela, C.W.; Pankhurst, R.J.; Casquet, C.; Baldo, E.G.; Galindo, C.; Fanning, C.M.; Dahlquist, J.A. 2010. The Western Sierras Pampeanas: Protracted Grenvilleage history (1330-1030 Ma) of intra-oceanic arcs, subduction-accretion at continental-edge and AMCG intraplate magmatism. Journal of South American Earth Sciences 29: 105-127.

Rapela, C.W.; Verdecchia, S.O.; Casquet, C.; Pankhurst, R.J.; Baldo, E.G.; Galindo, C.; Murra, J.A.; Dahlquist, J.A.; Fanning, C.M. 2016. Identifying Laurentian and SW Gondwana sources in the Neoproterozoic to Early Paleozoic metasedimentary rocks of the Sierras Pampeanas: Paleogeographic and tectonic implications. Gondwana Research 32: 193-212.

Seia, L.E. 1996. Las metamorfitas del sector sur y sureste de la Sierra de Pie de Palo (San Juan - Argentina). 
Ph.D. Thesis (Unpublished), Universidad Nacional de Córdoba: 105 p.

Standley, C.E.; Harris, R. 2009. Tectonic evolution of forearc nappes of the active Banda arc-continent collision: Origin, age, metamorphic history and structure of the Lolotoi Complex, East Timor. Tectonophysics 479: 66-94.

Steenken, A.; Siegesmund, S.; López de Luchi, M.G.; Frei, R.; Wemmer, K. 2006. Neoproterozoic to Early Palaeozoic events in the Sierra de San Luis: implications for the Famatinian geodynamics in the Eastern Sierras Pampeanas (Argentina). Journal of the Geological Society 163: 965-982.

Stüwe, K. 1997. Effective bulk composition changes due to cooling: a model predicting complexities in retrograde reaction textures. Contributions to Mineralogy and Petrology 129: 43-52.

Thomas, W.A.; Astini, R.A. 2003. Ordovician accretion of the Argentine Precordillera terrane to Gondwana: A review. Journal of South American Earth Sciences 16: 67-79.

Tibaldi, A.M.; Álvarez-Valero, A.M.; Otamendi, J.E.; Cristofollini, E.A. 2011. Formation of paired pelitic and gabbroic migmatites: An empirical investigation of the consistency of geothermometers, geobarometers, and pseudosections. Lithos 122: 57-75.

Tibaldi, A.M.; Otamendi, J.E.; Cristofolini, E.A.; Baliani, I.; Walker, B.A.; Bergantz, G.W. 2013. Reconstruction of the Early Ordovician Famatinian arc through thermobarometry in lower and middle crustal exposures,
Sierra de Valle Fértil, Argentina. Tectonophysics 589: 151-166.

van Staal, C.R.; Vujovich, G.I.; Currie, K.L.; Naipauer, M. 2011. An Alpine-style Ordovician collision complex in the Sierra de Pie de Palo, Argentina: Record of subduction of Cuyania beneath the Famatina arc. Journal of Structural Geology 33: 343-361.

Vujovich, G.I.; Kay, S.M. 1998. A Laurentian? Grenvilleage oceanic arc/back-arc terrane in the Sierra de Pie de Palo, Western Sierras Pampeanas, Argentina. In The proto-Andean margin of Gondwana (Pankhurst, R.J.; Rapela, C.W.; editors), Geological Society, Special Publication 142: 159-179. London.

Vujovich, G.I.; van Staal, C.R.; Davis, W. 2004. Age constraints on the tectonic evolution and provenance of the Pie de Palo Complex, Cuyania composite terrane, and the Famatinian Orogeny in the Sierra de Pie de Palo, San Juan, Argentina. Gondwana Research 7: 1041-1056.

White, R.W.; Pomroy, N.E.; Powell, R. 2005. An in situ metatexite-diatexite transition in upper amphibolite facies rocks from Broken Hill, Australia. Journal of Metamorphic Geology 23: 579-602.

White, R.W.; Powell, R.; Holland, T.J.B. 2007. Progress relating to calculation of partial melting equilibria for metapelites. Journal of Metamorphic Geology 25: 511-527.

Whitney, D.L.; Evans, B.W. 2010. Abbreviations for names of rock-forming minerals. American Mineralogist 95: $185-187$.

Manuscript received: June 13, 2018; revised/accepted: October 31, 2019; available online: February 4, 2019. 
Tabla Suplementaria

\begin{tabular}{|c|c|c|c|c|c|c|c|c|c|c|c|c|c|c|c|c|c|c|c|c|c|c|}
\hline \multicolumn{23}{|c|}{ Muestra SPP-27002: Granate (Grt) } \\
\hline \multirow[b]{2}{*}{ Análisis } & \multirow[b]{2}{*}{$\begin{array}{c}\text { Ubica- } \\
\text { ción }\end{array}$} & \multirow[b]{2}{*}{$\mathrm{SiO}_{2}$} & \multirow[b]{2}{*}{$\mathrm{TiO}_{2}$} & \multirow[b]{2}{*}{$\mathrm{Al}_{2} \mathrm{O}_{3}$} & \multicolumn{2}{|c|}{$\%$ Peso } & \multirow[b]{2}{*}{ MnO } & \multirow[b]{2}{*}{ MgO } & \multirow[b]{2}{*}{$\mathrm{CaO}$} & \multirow[b]{2}{*}{$\mathrm{Si}$} & \multirow[b]{2}{*}{$\mathbf{T i}$} & \multirow[b]{2}{*}{ Al } & \multicolumn{3}{|c|}{ apfu ( 24 oxígenos) } & \multirow[b]{2}{*}{ Mg } & \multirow[b]{2}{*}{$\mathrm{Ca}$} & \multirow[b]{2}{*}{ Sum. } & \multicolumn{4}{|c|}{ Miembros finales } \\
\hline & & & & & $\mathrm{Cr}_{2} \mathrm{O}_{3}$ & $\mathrm{FeO}$ & & & & & & & $\mathrm{Cr}$ & $* \mathbf{F e}_{\text {tot }}$ & Mn & & & & Xalm & Xspss & Xgro & Xpy \\
\hline \multicolumn{23}{|c|}{ Grt incluido en St } \\
\hline Grt 6 & & 36,65 & 0,08 & 21,63 & 0,02 & 34,49 & 1,68 & 2,15 & 3,20 & 5,92 & 0,01 & 4,12 & 0,00 & 4,66 & 0,23 & 0,52 & 0,55 & 16,01 & 0,78 & 0,04 & 0,09 & 0,09 \\
\hline Grt 8 & & 36,32 & 0,07 & 21,64 & 0,03 & 33,73 & 1,21 & 2,37 & 4,46 & 5,87 & 0,01 & 4,12 & 0,00 & 4,56 & 0,17 & 0,57 & 0,77 & 16,06 & 0,75 & 0,03 & 0,13 & 0,09 \\
\hline Grt 9 & & 36,79 & 0,07 & 21,78 & 0,01 & 34,85 & 1,71 & 2,32 & 2,86 & 5,92 & 0,01 & 4,13 & 0,00 & 4,69 & 0,23 & 0,56 & 0,49 & 16,01 & 0,79 & 0,04 & 0,08 & 0,09 \\
\hline Grt 10 & & 36,63 & 0,04 & 21,75 & 0,03 & 34,31 & 1,90 & 2,17 & 2,87 & 5,92 & 0,00 & 4,14 & 0,00 & 4,64 & 0,26 & 0,52 & 0,50 & 16,00 & 0,78 & 0,04 & 0,08 & 0,09 \\
\hline Grt 11 & & 36,76 & 0,05 & 21,82 & 0,02 & 34,69 & 1,72 & 2,07 & 3,25 & 5,91 & 0,01 & 4,14 & 0,00 & 4,67 & 0,23 & 0,50 & 0,56 & 16,01 & 0,78 & 0,04 & 0,09 & 0,08 \\
\hline Grt 12 & & 36,53 & 0,02 & 21,42 & $-0,00$ & 33,93 & 1,61 & 2,18 & 3,41 & 5,94 & 0,00 & 4,10 & $-0,00$ & 4,61 & 0,22 & 0,53 & 0,59 & 16,01 & 0,77 & 0,04 & 0,10 & 0,09 \\
\hline Grt 13 & & 36,66 & 0,04 & 21,71 & $-0,00$ & 34,13 & 1,68 & 2,20 & 3,38 & 5,92 & 0,00 & 4,13 & $-0,00$ & 4,61 & 0,23 & 0,53 & 0,58 & 16,01 & 0,77 & 0,04 & 0,10 & 0,09 \\
\hline Grt 14 & & 36,51 & 0,07 & 21,52 & 0,05 & 34,19 & 1,67 & 2,14 & 3,04 & 5,93 & 0,01 & 4,12 & 0,01 & 4,65 & 0,23 & 0,52 & 0,53 & 15,99 & 0,78 & 0,04 & 0,09 & 0,09 \\
\hline Grt 15 & & 36,52 & 0,01 & 21,71 & 0,00 & 34,62 & 1,66 & 2,02 & 3,09 & 5,92 & 0,00 & 4,15 & $-0,00$ & 4,69 & 0,23 & 0,49 & 0,54 & 16,01 & 0,79 & 0,04 & 0,09 & 0,08 \\
\hline Grt 16 & & 36,49 & 0,03 & 21,50 & 0,00 & 34,37 & 1,82 & 2,12 & 3,08 & 5,93 & 0,00 & 4,12 & $-0,00$ & 4,67 & 0,25 & 0,51 & 0,54 & 16,01 & 0,78 & 0,04 & 0,09 & 0,09 \\
\hline Grt 17 & & 36,98 & 0,02 & 21,98 & 0,01 & 33,63 & 1,00 & 2,49 & 3,94 & 5,93 & 0,00 & 4,15 & 0,00 & 4,51 & 0,14 & 0,60 & 0,68 & 15,99 & 0,76 & 0,02 & 0,11 & 0,10 \\
\hline \multicolumn{23}{|c|}{ Perfil A: Grt1 - Grt2 } \\
\hline Grt 18 & $\begin{array}{l}\text { borde } \\
\text { Grt1 }\end{array}$ & 36,07 & 0,05 & 21,40 & 0,00 & 34,64 & 0,82 & 2,40 & 3,32 & 5,90 & 0,01 & 4,12 & $-0,00$ & 4,73 & 0,11 & 0,59 & 0,58 & 16,04 & 0,79 & 0,02 & 0,10 & 0,10 \\
\hline Grt 20 & & 36,79 & 0,01 & 21,81 & 0,00 & 34,45 & 2,09 & 1,73 & 3,07 & 5,94 & 0,00 & 4,15 & 0,00 & 4,65 & 0,29 & 0,42 & 0,53 & 15,98 & 0,79 & 0,05 & 0,09 & 0,07 \\
\hline Grt 21 & & 36,34 & 0,10 & 21,79 & 0,02 & 33,36 & 3,42 & 1,39 & 3,42 & 5,90 & 0,01 & 4,17 & 0,00 & 4,53 & 0,47 & 0,34 & 0,59 & 16,01 & 0,76 & 0,08 & 0,10 & 0,06 \\
\hline Grt 22 & & 36,48 & 0,03 & 21,51 & 0,03 & 32,56 & 4,99 & 1,17 & 3,48 & 5,92 & 0,00 & 4,11 & 0,00 & 4,42 & 0,68 & 0,28 & 0,60 & 16,02 & 0,74 & 0,11 & 0,10 & 0,05 \\
\hline Grt 23 & & 36,47 & 0,00 & 21,71 & 0,01 & 31,90 & 5,38 & 1,11 & 3,77 & 5,90 & $-0,00$ & 4,14 & 0,00 & 4,31 & 0,74 & 0,27 & 0,65 & 16,03 & 0,72 & 0,12 & 0,11 & 0,04 \\
\hline Grt 24 & & 36,32 & 0,10 & 21,84 & 0,02 & 31,09 & 5,78 & 1,13 & 3,74 & 5,88 & 0,01 & 4,17 & 0,00 & 4,21 & 0,79 & 0,27 & 0,65 & 16,01 & 0,71 & 0,13 & 0,11 & 0,05 \\
\hline Grt 25 & $\begin{array}{l}\text { núcleo } \\
\text { Grt1 }\end{array}$ & 36,37 & 0,06 & 21,58 & 0,01 & 31,03 & 5,87 & 1,08 & 3,79 & 5,91 & 0,01 & 4,13 & 0,00 & 4,22 & 0,81 & 0,26 & 0,66 & 16,01 & 0,71 & 0,14 & 0,11 & 0,04 \\
\hline Grt 26 & & 36,19 & 0,03 & 21,67 & $-0,00$ & 32,39 & 4,67 & 1,17 & 3,73 & 5,88 & 0,00 & 4,15 & $-0,00$ & 4,40 & 0,64 & 0,28 & 0,65 & 16,03 & 0,74 & 0,11 & 0,11 & 0,05 \\
\hline Grt 27 & & 36,36 & 0,04 & 21,54 & 0,03 & 33,09 & 3,90 & 1,39 & 3,44 & 5,91 & 0,01 & 4,13 & 0,00 & 4,50 & 0,54 & 0,34 & 0,60 & 16,02 & 0,75 & 0,09 & 0,10 & 0,06 \\
\hline Grt 28 & & 36,31 & 0,02 & 21,76 & $-0,00$ & 33,73 & 2,21 & 1,91 & 3,24 & 5,91 & 0,00 & 4,17 & $-0,00$ & 4,59 & 0,30 & 0,46 & 0,56 & 16,00 & 0,78 & 0,05 & 0,10 & 0,08 \\
\hline Grt 29 & & 36,44 & 0,03 & 21,86 & 0,04 & 35,12 & 1,65 & 1,99 & 3,06 & 5,88 & 0,00 & 4,16 & 0,00 & 4,74 & 0,22 & 0,48 & 0,53 & 16,03 & 0,79 & 0,04 & 0,09 & 0,08 \\
\hline
\end{tabular}




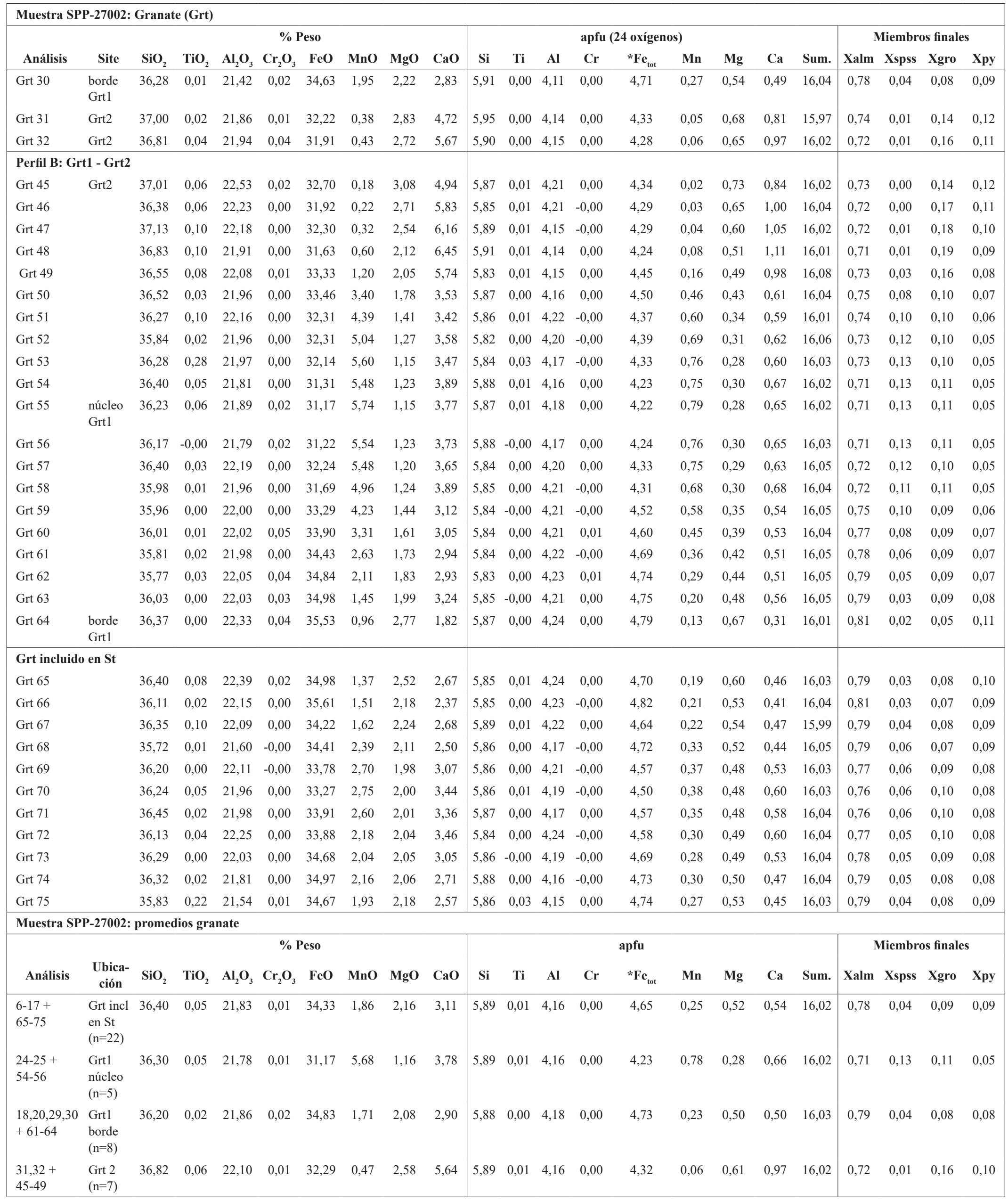




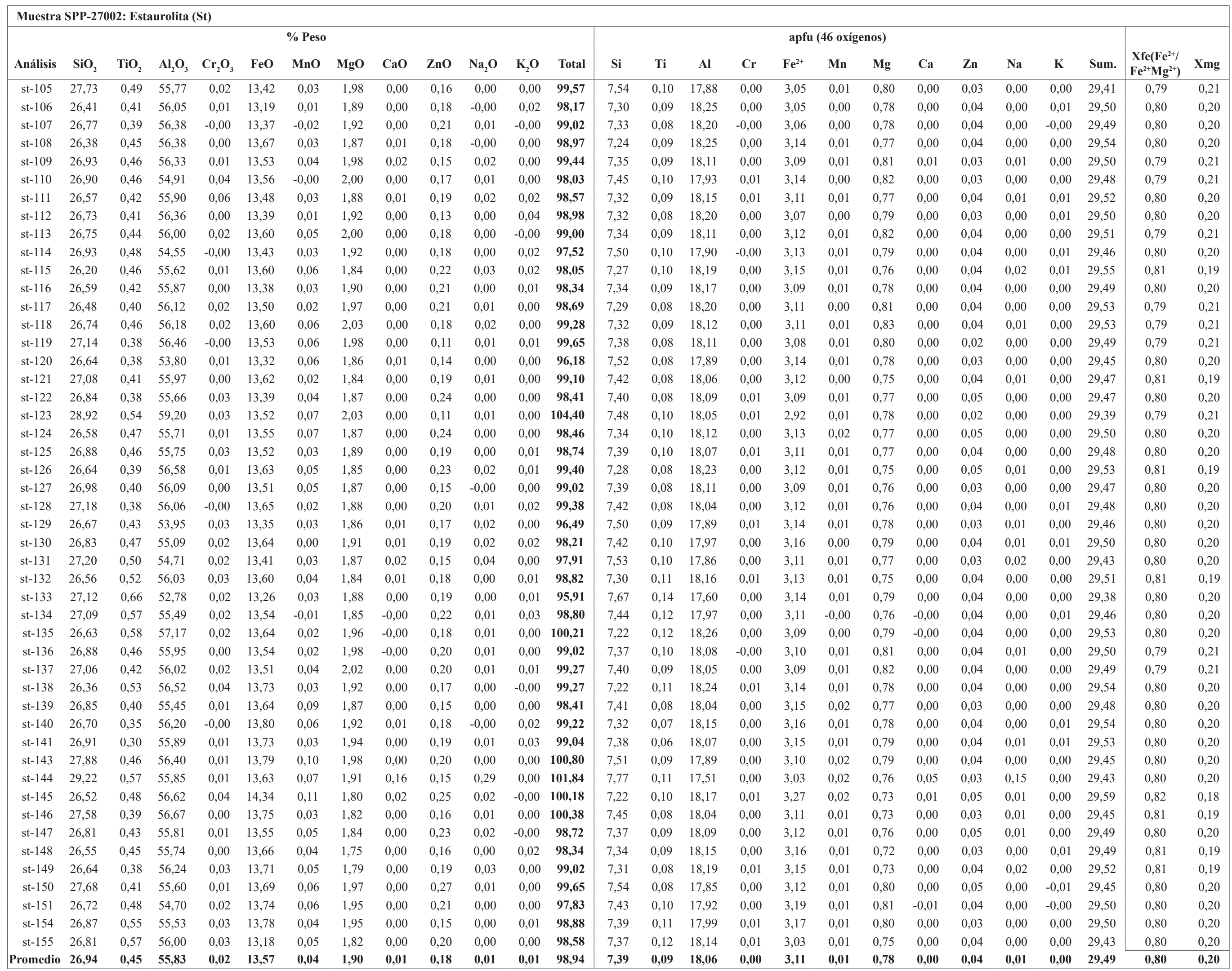




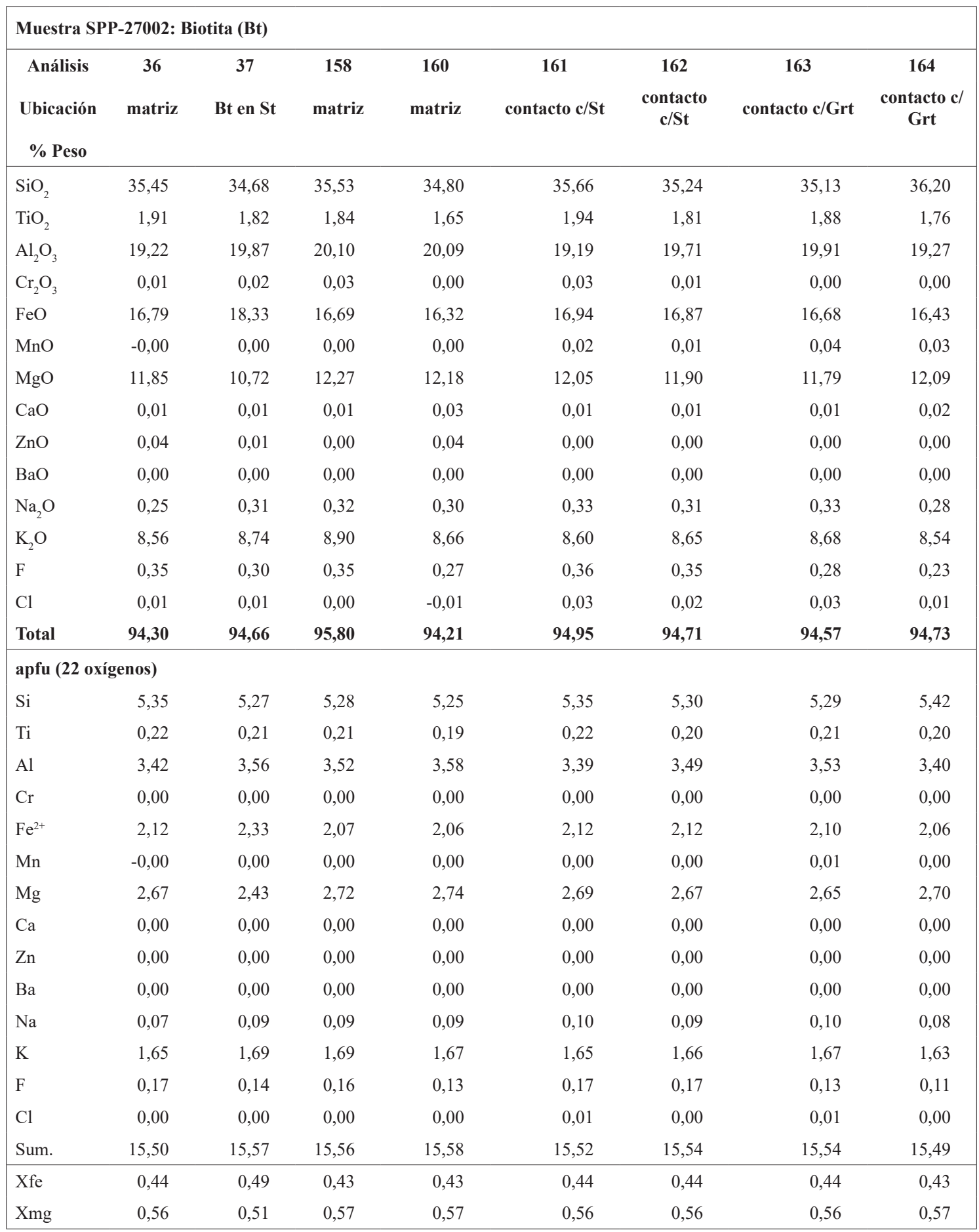




\begin{tabular}{|c|c|}
\hline \multicolumn{2}{|l|}{ Plagioclasa } \\
\hline \multicolumn{2}{|c|}{ Muestra SPP-27002 } \\
\hline $\begin{array}{l}\text { Análisis } \\
\text { \% Peso }\end{array}$ & Pl-156 \\
\hline $\mathrm{SiO}_{2}$ & 72,95 \\
\hline $\mathrm{TiO}_{2}$ & 0,00 \\
\hline $\mathrm{Al}_{2} \mathrm{O}_{3}$ & 17,44 \\
\hline $\mathrm{FeO}$ & 0,13 \\
\hline $\mathrm{MnO}$ & 0,00 \\
\hline $\mathrm{MgO}$ & $-0,00$ \\
\hline $\mathrm{CaO}$ & 5,45 \\
\hline $\mathrm{BaO}$ & 0,00 \\
\hline $\mathrm{SrO}$ & 0,06 \\
\hline $\mathrm{Na}_{2} \mathrm{O}$ & 4,11 \\
\hline $\mathrm{K}_{2} \mathrm{O}$ & 0,01 \\
\hline Total & 100,08 \\
\hline \multicolumn{2}{|c|}{ apfu (32 oxígenos) } \\
\hline $\mathrm{Si}$ & 12,51 \\
\hline $\mathrm{Ti}$ & 0,00 \\
\hline $\mathrm{Al}$ & 3,52 \\
\hline $\mathrm{Fe}^{2+}$ & 0,02 \\
\hline $\mathrm{Mn}$ & 0,00 \\
\hline $\mathrm{Mg}$ & $-0,00$ \\
\hline $\mathrm{Ca}$ & 1,00 \\
\hline $\mathrm{Ba}$ & 0,00 \\
\hline $\mathrm{Sr}$ & 0,01 \\
\hline $\mathrm{Na}$ & 1,37 \\
\hline $\mathrm{K}$ & 0,00 \\
\hline Sum. & 18,42 \\
\hline $\mathrm{Ab}$ & 0,58 \\
\hline An & 0,42 \\
\hline Or & 0,00 \\
\hline
\end{tabular}

\begin{tabular}{|c|c|c|}
\hline \multicolumn{3}{|c|}{ Muscovita } \\
\hline \multicolumn{3}{|c|}{ Muestra SPP-27002 } \\
\hline $\begin{array}{l}\text { Análisis } \\
\% \text { Peso }\end{array}$ & Ms 33 & Ms-165 \\
\hline $\mathrm{SiO}_{2}$ & 46,15 & 46,83 \\
\hline $\mathrm{TiO}_{2}$ & 0,27 & 0,33 \\
\hline $\mathrm{Al}_{2} \mathrm{O}_{3}$ & 35,48 & 35,13 \\
\hline $\mathrm{Cr}_{2} \mathrm{O}_{3}$ & 0,01 & 0,00 \\
\hline $\mathrm{FeO}$ & 1,22 & 1,63 \\
\hline $\mathrm{MnO}$ & 0,00 & 0,00 \\
\hline $\mathrm{MgO}$ & 1,12 & 1,17 \\
\hline $\mathrm{CaO}$ & $-0,00$ & 0,03 \\
\hline $\mathrm{Na}_{2} \mathrm{O}$ & 1,24 & 1,12 \\
\hline $\mathrm{K}_{2} \mathrm{O}$ & 9,20 & 9,22 \\
\hline $\mathrm{F}$ & 0,00 & 0,10 \\
\hline $\mathrm{Cl}$ & 0,00 & 0,01 \\
\hline Total & 94,58 & 95,47 \\
\hline \multicolumn{3}{|c|}{ apfu (22 oxígenos) } \\
\hline $\mathrm{Si}$ & 6,16 & 6,19 \\
\hline $\mathrm{Ti}$ & 0,03 & 0,03 \\
\hline $\mathrm{Al}$ & 5,58 & 5,47 \\
\hline $\mathrm{Cr}$ & 0,00 & 0,00 \\
\hline $\mathrm{Fe}^{2+}$ & 0,14 & 0,18 \\
\hline $\mathrm{Mn}$ & 0,00 & 0,00 \\
\hline $\mathrm{Mg}$ & 0,22 & 0,23 \\
\hline $\mathrm{Ca}$ & $-0,00$ & 0,00 \\
\hline $\mathrm{Na}$ & 0,32 & 0,29 \\
\hline $\mathrm{K}$ & 1,56 & 1,55 \\
\hline $\mathrm{F}$ & 0,00 & 0,04 \\
\hline $\mathrm{Cl}$ & 0,00 & 0,00 \\
\hline Sum. & 14,00 & 13,94 \\
\hline Xfe & 0,38 & 0,44 \\
\hline Xmg & 0,62 & 0,56 \\
\hline
\end{tabular}

\begin{tabular}{|lc|}
\hline \multicolumn{1}{|c|}{ Óxido } & $\begin{array}{c}\text { Límite de } \\
\text { detección } \\
\text { (\%) Peso) }\end{array}$ \\
\hline $\mathrm{SiO}_{2}$ & 0,05 \\
$\mathrm{TiO}_{2}$ & 0,05 \\
$\mathrm{Al}_{2} \mathrm{O}_{3}$ & 0,02 \\
$\mathrm{FeO}$ & 0,05 \\
$\mathrm{Fe}_{2} \mathrm{O}_{3}$ & - \\
$\mathrm{MnO}$ & 0,05 \\
$\mathrm{MgO}$ & 0,02 \\
$\mathrm{CaO}$ & 0,02 \\
$\mathrm{Na}_{2} \mathrm{O}$ & 0,02 \\
$\mathrm{~K}_{2} \mathrm{O}$ & 0,02 \\
$\mathrm{ZnO}$ & 0,07 \\
$\mathrm{~F}$ & 0,05 \\
$\mathrm{Cl}$ & 0,01 \\
$\mathrm{Cr}$ & 0,09 \\
$\mathrm{P}_{2} \mathrm{O}_{5}$ & 0,05 \\
$\mathrm{BaO}$ & 0,04 \\
$\mathrm{SrO}_{3}$ & 0,08 \\
$\mathrm{~V}_{2} \mathrm{O}_{3}$ & 0,09 \\
\hline
\end{tabular}

